\title{
MORPHOLOGY OF CANNABIS SATIVA L. ACHENES
}

by

\author{
Steve Govinda Udai Naraine, \\ Bachelor of Science in Medical Physics, 2013, Ryerson University
}

\begin{abstract}
A thesis presented to
Ryerson University

in partial fulfillment of the

requirements for the degree of

Master of Science

in the program of Molecular Science
\end{abstract}

Toronto, Ontario, Canada, 2018

(C) Steve Govinda Udai Naraine, 2018 


\section{AUTHOR'S DECLARATION}

I hereby declare that I am the sole author of this thesis. This is a true copy of the thesis, including any required final revisions, as accepted by my examiners.

I authorize Ryerson University to lend this thesis to other institutions or individuals for the purpose of scholarly research.

I further authorize Ryerson University to reproduce this thesis by photocopying or by other means, in total or in part, at the request of other institutions or individuals for the purpose of scholarly research.

I understand that my thesis may be made electronically available to the public. 


\author{
ABSTRACT \\ The Morphology of Cannabis sativa L. Achenes \\ Master of Science
}

2018

Steve Govinda Udai Naraine

Molecular Science

Cannabis sativa L. has been domesticated for fibre, oilseed, and marijuana; it also occurs as ruderal plants. "Marijuana" refers to plants selected for high concentrations of the chemical tetrahydrocannabinol (THC), while "hemp" refers to plants low in concentration of THC and which are domesticated for either stem fibre or oilseed. In my first chapter I review the botany of cannabis, taxonomy and origins, ethnobotany, and crop ferality. In my second chapter, I performed a study where achenes ("seeds") from herbarium collections representative of these classes of C. sativa were assessed for variation in morphological characters and pericarp resistance to fracture. Multivariate analysis of the data revealed significant divergence among the groups. In contrast to ruderal plants, domesticated plants (hemp or marijuana) possessed achenes that are significantly longer, heavier, covered with a less adherent perianth, and lacking a pronounced basal attenuation. These characteristics reflect traits that are advantageous in domesticated plants, and are consistent with the "domestication syndrome". Marijuana achenes, in comparison with hemp achenes, are shorter and darker. Achenes of fibre cultivars are larger than the achenes of oilseed cultivars. Achenes of dioecious oilseed cultivars are larger than the achenes of monoecious oilseed cultivars. We propose several mechanisms by which this phenotypic divergence may have occurred, including potential differences in outcrossing rate and the evolution of life history strategies among $C$. sativa groups that deserve further exploration. While only one species of Cannabis merits recognition, we postulate these phenotypic differences in C. sativa are a result of domestication for different purposes. In my final chapter I discuss the limitations and future studies. This work contributes a more complete understanding of cannabis morphology to the greater body of literature on plant domestication. 


\section{ACKNOWLEDGEMENTS}

The author gratefully acknowledges the funding support from the Natural Sciences and Engineering Research Council (NSERC) Discovery Grants program (no. 402305-2011 to Dr. Campbell). In addition, I appreciate the support of Agriculture and Agri-Food Canada (AAFC) herbarium staff: a special thank you in particular to Brenda Brookes for her support and assistance in preparation of several figures. Ryerson University Department of Physics, provided force measuring software and equipment; Mike Neiser, for continuing to bring my imagination, and inventiveness to reality, i.e., building the seed force press; and Michelle Dupuis, for kind words and sharing in the observing of seeds. Thank you to my M.Sc. supervisor, Dr. Lesley Campbell, supervisory committee members, Drs. Ernest Small and Andrew Laursen, for your advice and guidance, as well as my examination committee, which also included Drs. Bryan Koivisto and Russell Viirre, for critical improvements to this document.

Many thanks to Solace Health Inc (TerrAscend, TER:CNX), especially Vijay Sappani, Micheal Nashat, and Basem Hanna for funding support. Ernest Small, a trusted advisor, a mentor and a friend; I cannot begin to express the level of respect, gratitude and admiration that I for you. You encouraged me, taught me everything from, theories and ideology, to discipline and perspectives on life. I dearly enjoy the laughter and learning that we have shared over the past 4 years. I would like to thank my mother, Lillowtie and my father, Mooldat Naraine, for nurturing my curiosities and having patience with me. They are the backbone of my success and allowed me the opportunity to grow and dream. 


\section{DEDICATION}

Mom \& Dad for the supporting me in victories and defeats; Ernest Small, for taking the time to teach, listen and bestowing wisdom. To my Nana (Grandfather), Ramdas, whom I know would be proud of my accomplishments. Everyone that believed in me and encouraged when others would have discouraged. When I stand, I do not stand alone; I stand with all those who cared for me, friends, family and colleagues.

Dreams are the seed of change,

Nothing ever grows without a seed, and

Nothing ever changes without a dream

- Debby Boone

...if rice were to disappear from the face of the Earth, Billions of people would die;

If marijuana were to disappear from the face of the Earth, Billions of people would cry...

- Dr. Ernest Small 


\section{TABLE OF CONTENTS}

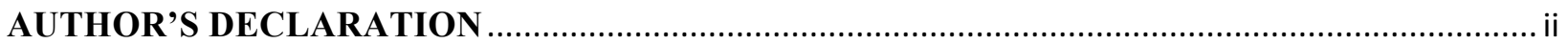

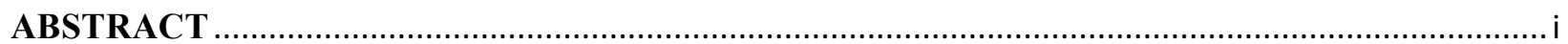

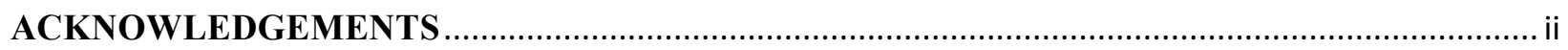

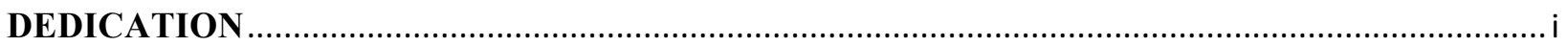

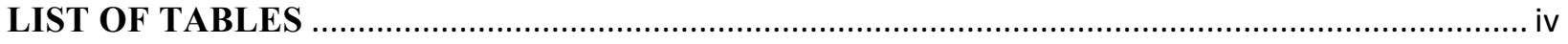

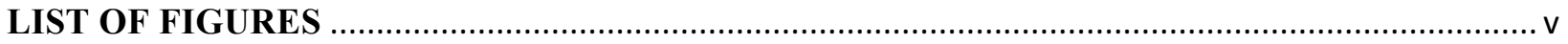

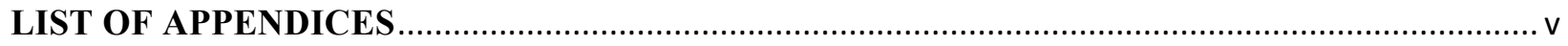

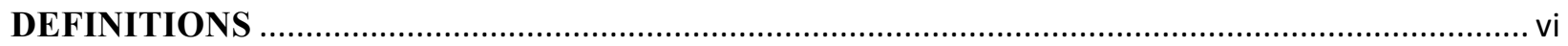

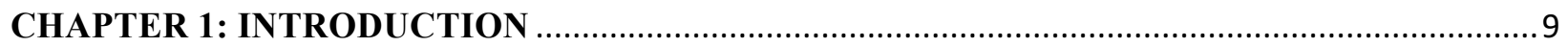

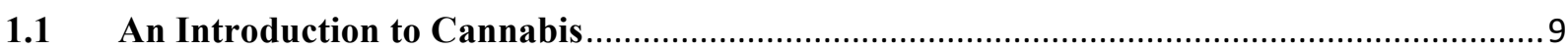

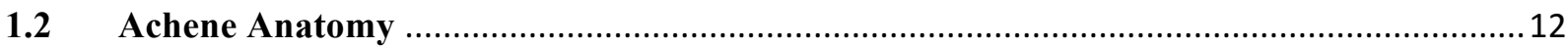

1.3 Human History of Cultivating and Using Cannabis.................................................... 15

1.4 Domestication Syndrome: Consistent Differences Between Crops and Wild Relatives .....17

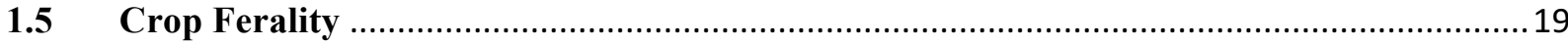

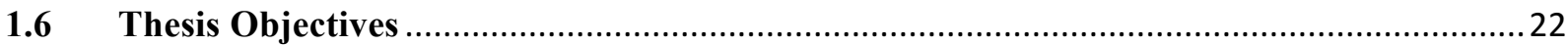

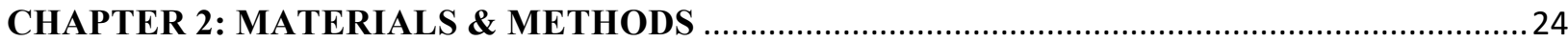

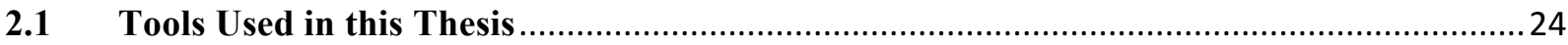

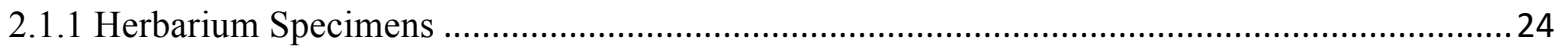

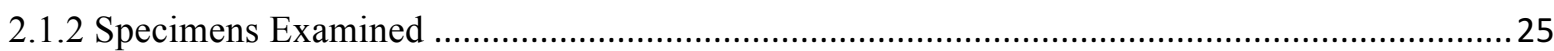

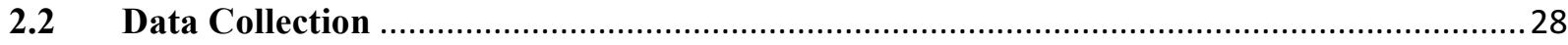

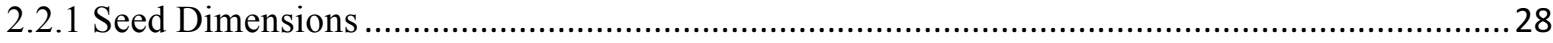

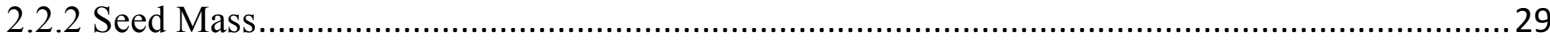

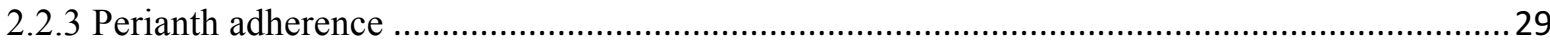

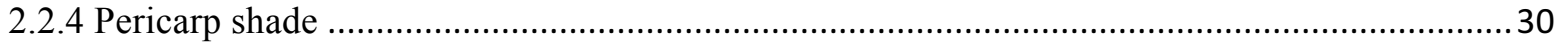

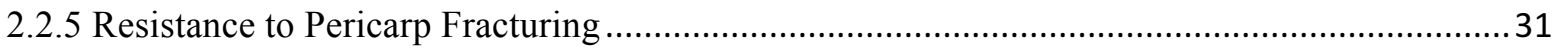

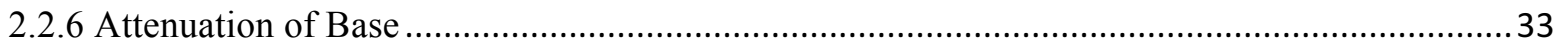

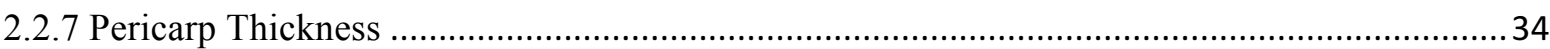

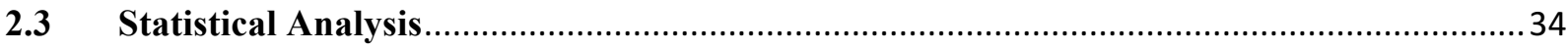

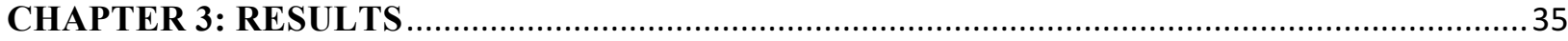

3.1 Differences Between Domesticated (Hemp and Marijuana) and North-Temperate, LowTHC Ruderal Plants 
3.2 Differences Between Hemp and Marijuana Genotypes

3.3 Differences Among Dioecious Fibre, Dioecious Oilseed, and Monecious Oilseed

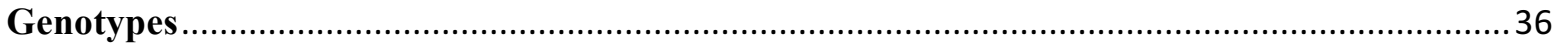

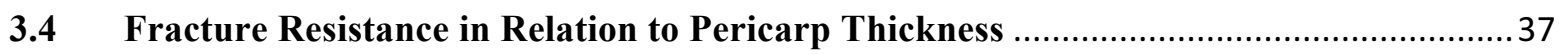

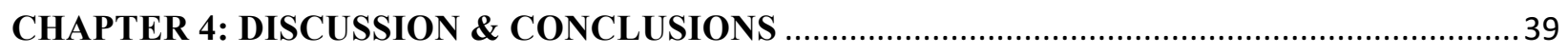

4.1 Cannabis Crop Seeds are Larger than Ruderal Seeds ...................................................40

4.2 Marijuana Seeds are Smaller and Lighter than Hemp Seeds........................................ 43

4.3 Fibre Hemp Seeds are Heavier than Oilseed Hemp Seeds ............................................4 43

4.4 Dioecious Genotypes Produce Heavier Seeds than Monoecious Genotypes.......................44

4.5 Thick Pericarps Protect Achenes from Fracturing …..................................................... 44

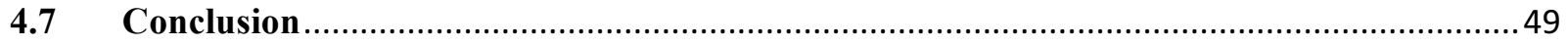

APPENDIX I - IMAGE ANALYSIS: MATLAB CODE ........................................................ 50

6.1 Programming code to import images to MATLAB and convert it into a matrix ..............50

6.2 Programming code to calculate greyscale of achenes ...........................................................50

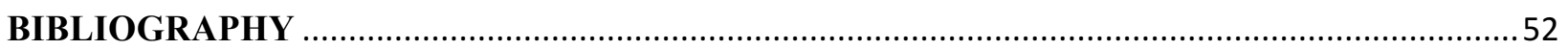




\section{LIST OF TABLES}

Table 2.1 - Collectors and DAO accession numbers, and cultivar names (where available).

Table 3.1a - One-way ANOVA of the three genotypes (hemp, grouping oilseed and fibre classes; marijuana; and north-temperate ruderal) with post-hoc Tukey-Kramer

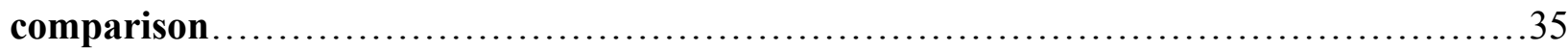

Table 3.1b - Comparison of Pericarp Thickness and Shade............................ 35

Table 2.2 - One-way ANOVA of three hemp genotypes (dioecious fibre, dioecious oilseed and monoecious oilseed) with post-hoc Tukey-Kramer comparison......................37

Table 4.1 - Characteristic Traits of a Domestication Syndrome......................40

Table 4.2 - One-way ANOVA comparing low-THC north-temperate ruderal accessions and high-THC semi-tropical (Indian) ruderal accessions..................................48 


\section{LIST OF FIGURES}

Figure 1 - Cannabis sativa Differentiated Groups.................................. 12

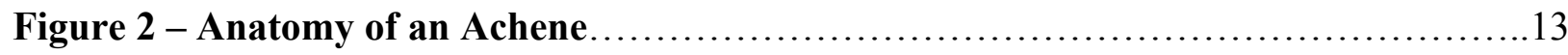

Figure 3 - Differentiation between Ruderal and Domesticated Cannabis sativa seeds.....15

Figure 4 - Old hemp seed of UC-RGM. Seed still embedded in the flower................22

Figure 2.1 - Representative example of 'kafiristanica' (Cannabis sativa subsp. indica var.

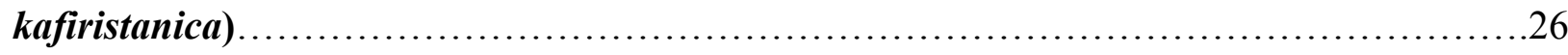

Figure 2.2 - Shape of an achene of Cannabis sativa, showing dimensions measured.........29

Figure 2.3 - Achenes of Cannabis sativa, showing variation in perianth adherence..........30

Figure 2.4 - Comparison of pericarp darkness in achenes domesticated for hemp and for

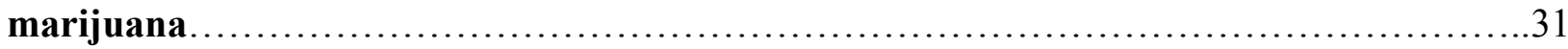

Figure 2.5 - Tool to measure the force needed to crack a seed.........................32

Figure 2.6 - Force press to measure resistance to pericarp fracturing $\ldots \ldots \ldots \ldots \ldots \ldots \ldots . \ldots . \ldots 33$

Figure 2.7 - Outlines of achenes of Cannabis sativa, showing scoring of basal

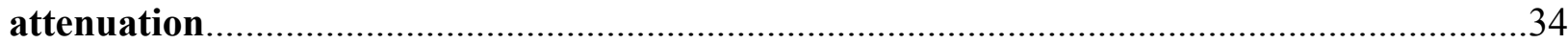

Figure 3.1 - The relationship between pericarp thickness to fracturing force..............38

Figure 4.1 - Domesticated and ruderal achene of Cannabis sativa compared..............42

Figure 4.2 - Utilitarian Divergence of Cannabis sativa ............................. 46

LIST OF APPENDICES

APPENDIX I - IMAGE ANALYSIS: MATLAB CODE ..............................50 


\section{DEFINITIONS}

Abscission: the detachment or removal of plant parts from the main portion of the plant. and is commonly seen in senescence of old leaves and in ripe fruit.

Achene: an indehiscent (never naturally opening) single-seeded fruit with dry pericarp contiguous to the seed but still distinguishable from the testa (Stuppy 2004).

Angiosperms: plants that produce flowers for sexual reproduction. Ovules and seeds are protected by closed units in angiosperms. Seeds are formed after fertilization of the flowers by pollen grains.

Basal Attenuation: the narrowing of the base of the achene.

Caryopsis: one-seeded fruit of a grasses (Gramineae).

Chemotype (chemovar): the chemical "fingerprint" of a plant or microorganism. Differences within are often in secondary metabolic compounds.

Cotyledon: the first leaf or pair of leaves of a plant embryo.
Cultivar: a selectively bred and cultivated plant that can be defined as its own distinct variety.

Dicotyledonous: also known as dicots, are a group of angiosperms that are characterized by embryos that express two cotyledons within.

Domestication: the outcome of a selection process that leads to increased adaptation of plants, fungi, and/or animals to cultivated environments or rearing and use by the domesticator (Gepts 2004).

Domestication Syndrome: phenotypic traits which evolve during the process of domestication that can distinguish cultivated plants from wild type ancestor plants.

Glandular Trichomes: trichomes are specialized hairs that protrude from the epidermal tissue of most vascular plants. They are multicellular and responsible for a significant portion of a plant's secondary chemistry.

Inflorescence: a floral unit, a group or cluster of flowers on a stem including stalks, bracts and flowers. 
Infructescence: an inflorescence that is comprised of one or more pericarpia; a flower in the fruiting stage of life.

Phenotype: the observable expression of activated genes resulting from the interaction of its genotype with the environment.

Perianth: collectively the petals and sepals, with regards to female cannabis flowers is transformed to a layer enveloping the outer most part of the achene.

Pericarp: part of the fruit that forms the outer shell when ripened.

Propagule: a structure that can become detached from a plant and give rise to a new plant.

Rachis: the stem of a plant, especially a grass, bearing flowered stalks at short intervals.
Ruderal: a plant that is growing, in disturbed soil, outside of cultivation in nature.

Sepal: In flowers, the outer layer of the perianth.

Shattering: is the disarticulation of the achene from the flower and ultimately its dispersal. As the achene matures it is released form the plant.

Spike: an elongated inflorescence with alternate sessile flowers along a single axis, if branched, then the smaller branches are called spikelets.

Syndrome: is a collection of traits that consistently occur together in a set.

Tepals: is the outer part of a flower including the petals and sepal.

Weedy Species: is a plant that grows in a location where humans do not want it to grow. 


\section{CHAPTER 1: INTRODUCTION}

\subsection{An Introduction to Cannabis}

Cannabis sativa (Cannabaceae, Eudicot, Angiosperm) plants are generally dioecious (and rarely monoecious) and thus possesses unisexual flowers that are wind pollinated (Amaducci, Coluzzi, Zatta, \& Venturi, 2008). Cannabis plants produce achenes that are have very thin perianths (Small E. , 2015). Seeds appear camouflaged due to the patterning of the perianth and potentially the venation of the pericarp (Small E. , 1974); suggested to be influenced by the soil background and geography (Stevens, 2007). Fresh seeds often take between 3 to 7 days to germinate (Clarke \& Merlin, 2013). The straightening of the hypocotyl, emerges the slightly unequal cotyledons (the seedling leaves are rounded and not serrated (Small \& Antle, 2007).Commonly recognized for its serrated leaflets comprising the compound leaf, the seeds of this plant will germinate and grow in well drained and/or disturbed soils, preferring open sunny environments (Small E. , 2015). The rate of growth is incredibly quick, and plants can grow to a height of 6 meter (about 20 feet) (Small E. , 2015). This rapid growth contributes to the relatively high requirement for water and nutrients (Caplan, Dixon, \& Zheng, 2017a; Caplan, Dixon, \& Zheng, 2017b). Plants are photoperiod sensitive and require lengthening dark periods (with shortened days) to initiate flowering in male and female plants (Small E. , 2015). Male flowers mature faster and die earlier than the female flowers (Bouquet, 1950). Given the chance to be pollinated, the female flower will produce an achene which will disarticulate once mature and remain dormant until the following spring. Cannabis growth seasons usually range from $4-6$ months for all stages of life cycle (seed to harvest). 
There is a large amount of phenotypic variation in many varieties of cannabis, this is noticeable in both the growth patterns and more interestingly the chemotypes (De Meijer, et al., 2003). There are 3 distinct chemotypes of C. sativa as described by Dr. Ernest Small (Small \& Cronquist, 1976). The types are described according to the ratio of tetrahydrocannabinol (THC) to cannabidiol (CBD): type 1 high:low, type 2 low:high, and type 3 1:1. These include hemp and marijuana varieties, marijuana which is described as having more than $0.3 \% \mathrm{w} / \mathrm{w}$ tetrahydrocannabinol (THC) and hemp which has less than $0.3 \% \mathrm{w} / \mathrm{w}$ (Small \& Cronquist, 1976).

Most authorities hypothesize that the species, C. sativa, arose in northern India/Pakistan border (Schultes, 1970; Clarke \& Merlin, 2013), but no extant plants have been identified which can be reliably identified as representative of the original population before the plant came under the influence of humans (Small E. , 2016). Escaped populations of weedy crop-derived plants grow outside of cultivation in many parts of the world, commonly in disturbed soils near ditches and streams (Small, Pocock, \& Cavers, 2003). Such ruderal plants have evolved adaptations to local environments (Small E. , 2015). For example, they have shortened lifecycles such that ruderal populations flower an Wild Cannabis is hypothesized to have originated in the Himalayan mountains at the boarder of Pakistan and India. Cannabis was one of the first cultivated plants, and domestication occurred approximately 10000 BCE (Li, 1973). Now, Cannabis is cultivated around the world, indoor and outdoor, for both medical and recreational purposes. Any Cannabis plants found in nature in Pakistan or India would be virtually impossible to tell whether it was wild or ruderal; however, elsewhere, Cannabis growing outside of cultivation is considered ruderal. Wild being never cultivated by humans in its lineage and 
ruderal being 'the first to cultivate disturbed lands', fruit before killed by frost (Small, Pocock, \& Cavers, 2003).

Three cultigen groups have been domesticated (Clarke \& Merlin, 2013) (Small 2015). For at least 6000 years, the plant has been grown in north temperate areas, primarily as a fibrous stem crop, to a much lesser degree for oilseed. These two "industrial hemp" cultigens have very limited levels of the euphoriant chemical tetrahydrocannabinol (THC), but relatively high amounts of the non-euphoriant compound cannabidiol (CBD). In warm-temperate to subtropical areas, the plant has been grown primarily as a source of drug preparations, such as marijuana and hashish. The drug cultigen, in contrast to the fibre and oilseed cultigens, characteristically is high in THC, low in CBD. The domesticated plants have been recognized as "land races," "cultivars," and "strains" (note that Article 2.2 of the nomenclatural code for cultivated plants (Brickell, et al., 2016) forbids the use of the term "strain" as equivalent to "cultivar.") The cultigens and ruderal plants have been treated taxonomically in various ways (Small \& Cronquist, 1976; Small E. , 2015; Small E. , 2016; Small E. , 2017). The following nomenclature is applicable to the three cultigens and the ruderal plants examined for this study: subsp. sativa var. sativa (fibre and oilseed cultivars); subsp. sativa var. spontanea Vavilov (low-THC ruderal plants); subsp. indica (Lam.) Small \& Cronq. var. indica (Lam.) Wehmer (marijuana strains).

A previous study (Small E. , 1974) indicated that there are significant morphological differences between achenes ("seeds") of ruderal and domesticated C. sativa, but very little is known about the possible differences among domesticated forms (marijuana strains, fibre cultivars, oilseed cultivars), the subject of the present investigation. Although the seeds represent only a small part of the phenotype of C. sativa, they are, of course, critical to its survival, as well as providing an important economic product, and so merit special attention. 


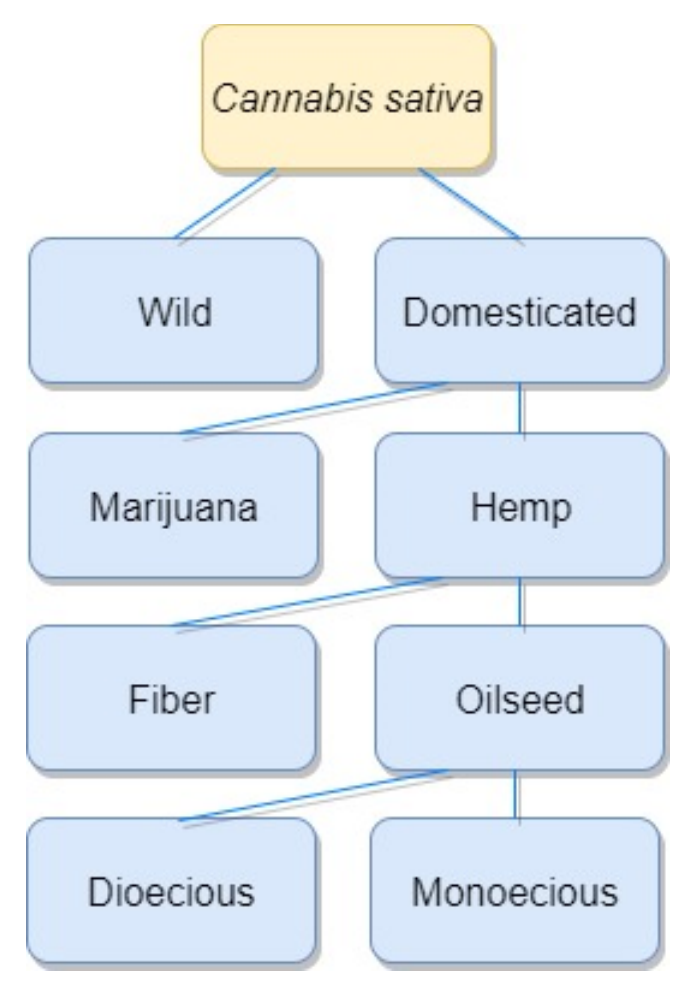

\section{Figure 1.1 - Cannabis sativa Differentiated Groups}

Cannabis sativa was domesticated for two purposes, high THC marijuana and low THC hemp. Hemp stem is used for fibre and the seeds are used for oilseed. Recently, monoecious varieties of oilseed hemp have been bred as oppose to the naturally occurring dioecious types.

\subsection{Achene Anatomy}

Because I am studying the anatomy of a particular type of fruit (an achene), I first introduce the key morphological features of this important life stage. Achenes are also the form of fruit possessed by corn, wheat and sunflower seeds. Many plants sexually reproduce via seeds, which may be dispersed individually or within fruits. Cannabis sativa disperses a single seed contained within a non-fleshy fruit, known as an achene (Small E., 1974). Achenes contain a single seed covered by a thin but durable fruit wall called a pericarp and throughout my thesis, I use the terms achene and seeds interchangeably (although in this section I will use carefully applied language to avoid confusion). 
Travelling length-wise on the achene, there are two ends to the pericarp, the basal side (labelled base, in Figure 1.2) and the opposite side possesses has the micropyle and micropylar plug. The pericarp has three distinct layers (listed from exterior inward): exocarp, mesocarp and endocarp (to part that immediately surrounds the seed). On the inside of the pericarp, there is a white embryo that, if germinated, will give rise to the seedling.

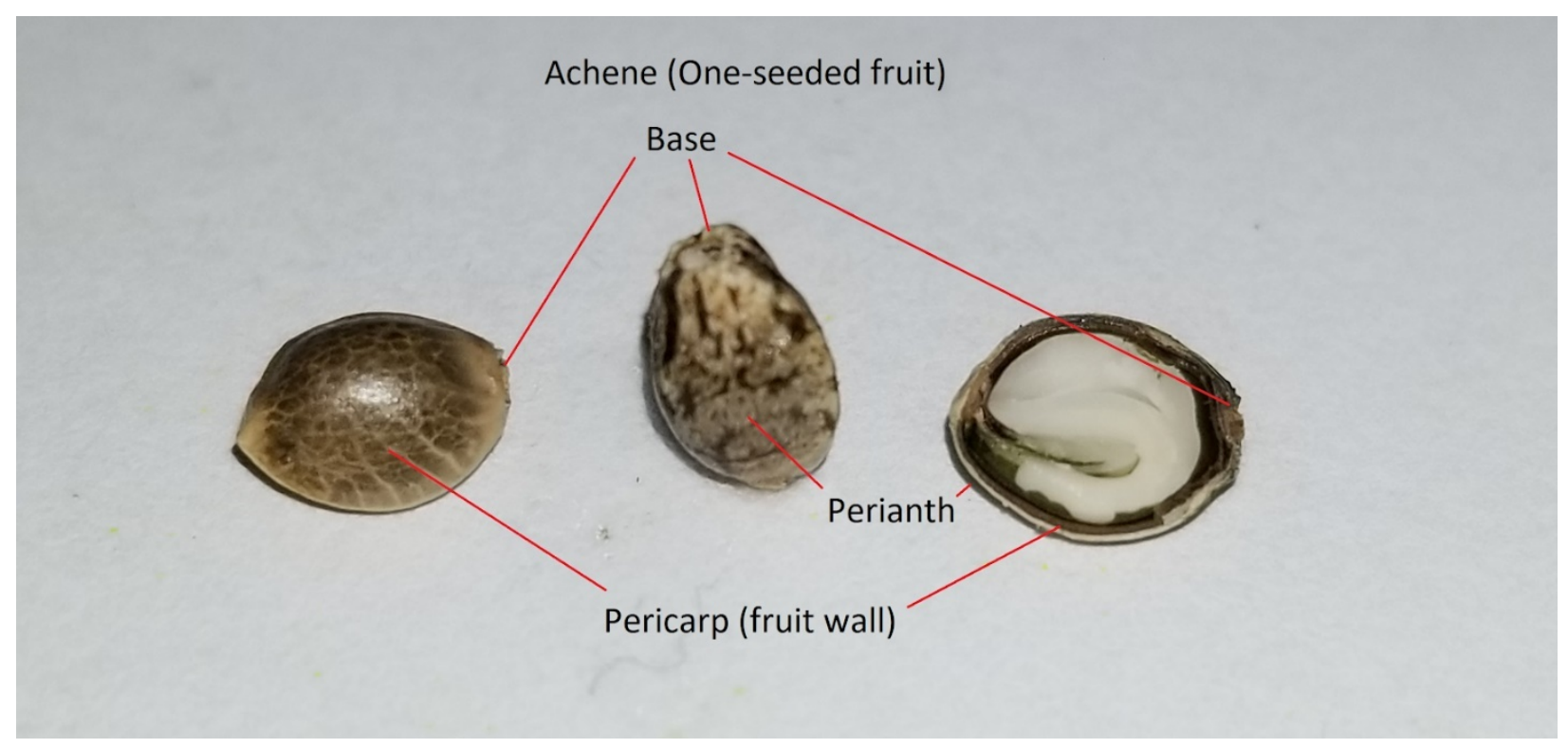

Figure 1.2 - Anatomy of an Achene

An achene is a one-seeded fruit, therefore having a pericarp (fruit wall). The cross section on the right clearly illustrates the white embryo in the center and the thickness of layers in the pericarp (lighter beige) and perianth (darker brown).

The embryo (seen in white, Figure 1.2) has two cotyledons that will be the first photosynthetic appendages to appear once the seed emerges from the soil. The outer cotyledon is larger than the inner, and they both envelop the meristem (undifferentiated cells that generate new cells for growth) that will generate the first true leaves. Where the cotyledons connect (the 
shoot meristem) and then curve around to point to the micropyle plug is the radicle. The radicle later develops into the root of the mature plant.

Previous research on the morphology of Cannabis achenes has made some headway in my focal research area (Small E. , 1974). Dr. Small measured achene length, base elongation, and adherence of perianth using 100 seeds of fibre cultivars, 39 seeds from illicit drug trade confiscations (marijuana) and 257 seeds of wild varieties. A biometric index was used to score the length with assigned values as: 0, longer than $3.9 \mathrm{~mm} ; 1,3.7-3.9 \mathrm{~mm} ; 2,3.3-3.6 \mathrm{~mm}$; and 3, shorter than $3.3 \mathrm{~mm}$. A similar index was used to score the elongation of the base and development of perianth.

Small (1974) discovered that domesticated Cannabis achenes, when compared with their wild relatives, were larger and were lacking a perianth. The cultivated varieties had a very little basal attenuation if any, lending to a poor abscission zone. Dr. Small (1974) hypothesized that ancient cultivators may have buried seeds deeper as a strategy to avoid herbivory (i.e., birds eating shallow-planted seeds), and this planting strategy may have unconsciously selected for larger seeds in domesticated vs. unmanaged plant populations. Dr. Small (1974) also suggested that unconscious selection by humans likely also reduced basal attenuation of achenes, dark colouration of pericarps, and perianth coverage, as well. An ancient cultivator may have picked seed from the inflorescence (a flower with complex architecture), seeds that were readily apparent to them. This thesis will be more encompassing with the addition of seed width, height and force needed to fracture the achene. It will also be more precise by using continuous data where possible for example analyzing the length in millimeters instead of grouping them into a biometric index. Here I have analyzed more individual seeds and expanding my hemp varieties 
to represent new oilseed cultivars that did not exist in 1974 such as 'Canma', 'Finola', and 'Alyssa'.
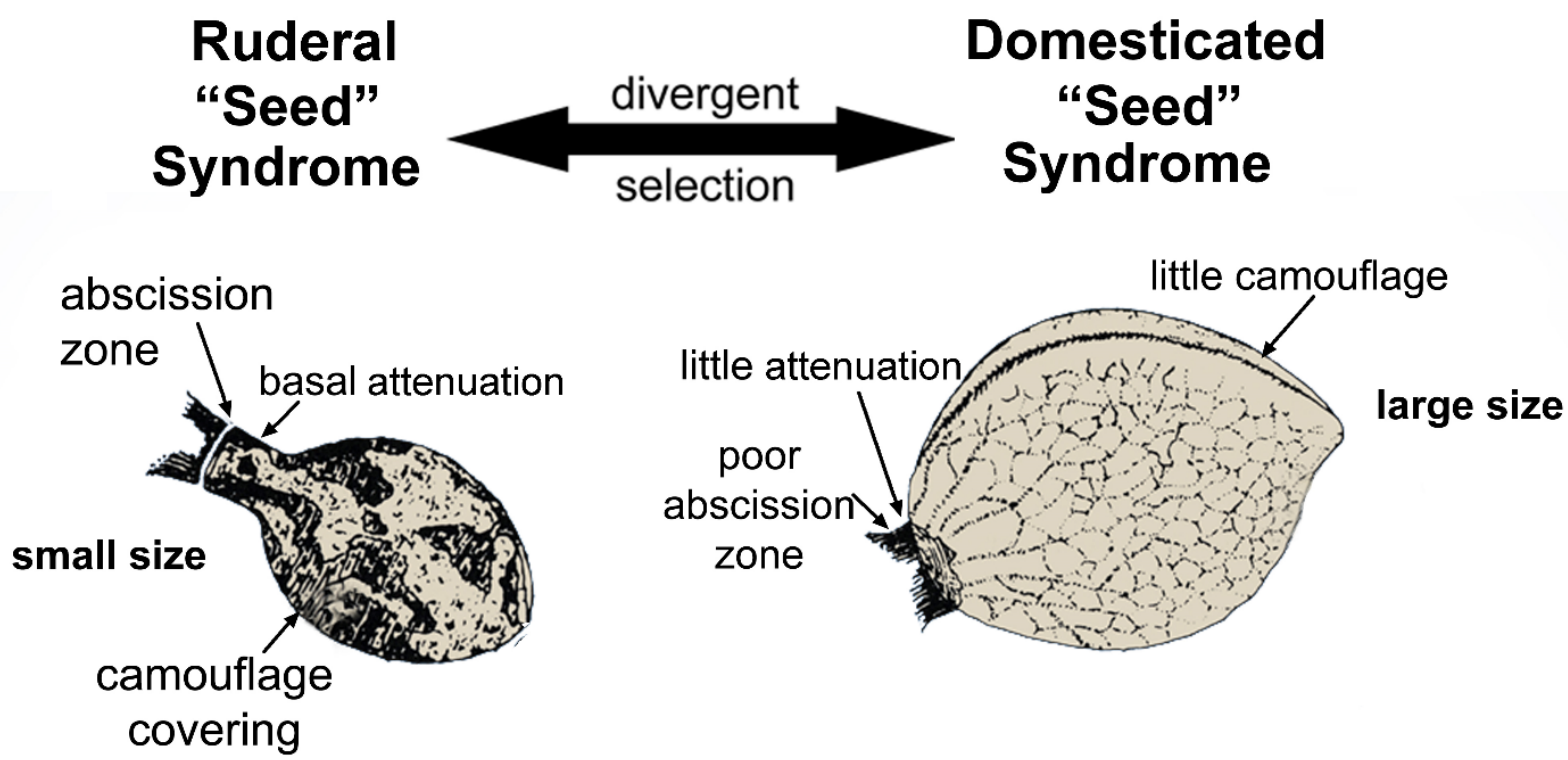

Figure 1.3 - Differentiation between Ruderal and Domesticated Cannabis sativa seeds Notice that the ruderal seed (left) is smaller, retained perianth, and has an attenuated base that aides in abscission when compared to the domesticated seed (right).

\subsection{Human History of Cultivating and Using Cannabis}

Humans have cultivated Cannabis for millennia (Jiang, et al., 2006) and over the past century it has become a controlled/regulated crop for most jurisdictions around the world. Humans have domesticated this plant for various reasons, implementing an assortment of selection over millennia. The ethnobotany of man and marijuana dates back over 2500 years, as shoots, leaves and fruits of cannabis were unearthed in the Yanghai Tombs, Turpan district in Xinjiang, China (Jiang, et al., 2006). In this particular case it is assumed that it was used for 
ritualistic/medicinal purposes, given the shamanistic ancestry of the deceased. Today, there are still small groups or tribes around the world that continue the traditions of marijuana consumption for rituals and religious purposes (Clarke \& Merlin, 2013).

Cultivation is usually for one of three distinct purposes: fiber, oilseed or cannabinoids (drug production). Hemp fiber and seed types have been bred for different parts of the same plant, fiber production focuses on the stem and prolonged vegetation; whereas in seed production it is essential to have fully matured and fertilized flowers. Human selection for fiber and cannabinoids has been going on for generations unlike artificial selection for achenes is very recent and limited to oilseed production. The current varieties of domesticated marijuana in the western world are what supply the medical marijuana industry. The demand for medical marijuana is growing in many countries such as Canada, parts of Australia, parts of the United States, Croatia, Colombia, and Chile just to name a few. Given the increase in medical marijuana production the risk of escaped pollen fertilizing ruderal hemp is concerning.

Cannabis is endogenous to Eurasia, and phytocannabinoids are uniquely derived from this plant. Since domestication Cannabis has been cultivated on all continents (except Antarctica) and has escaped cultivation repeatedly, which makes it difficult to control the movement of these pharmaceutically important chemicals. If the purpose of cannabinoids being produced in the plant are adaptive to natural environments, then we will see an increase of these compounds in ruderal populations. This poses a problem for controlling the production of cannabinoids since they will be produced and more concentrated in the glandular trichomes of ruderal plants when compared to crop populations. The wild traits can also be a means of control, for example the hardness and thickness of the testa that protects the seed from mechanical and chemical damage. 


\subsection{Domestication Syndrome: Consistent Differences Between Crops and Wild Relatives}

To maximize harvest of the stored food in seeds, humans have frequently altered the phenotype of the plants, especially the morphology and physiology of seeds. When crops are domesticated, their seed morphology and physiology evolves away from that of their wild relatives in relatively similar patterns across crop species, including the loss of shattering (or dropping seeds once mature from the inflorescence) and reduced dispersal, increases in seed size, and changes in resistance to herbivory or palatability (Meyer, DuVal, \& Jensen, 2012). Below I illustrate this point with several crop-specific examples.

Increases in seed size, seed number, and changes in seed shape as a result of domestication is a consistent pattern documented in carrot, grape, and cereals. For instance, domesticated carrot (Daucus carota L.) "seeds" tend to be larger than those of related wild carrot populations (Small E. , 1978). Moreover, the achenes of domesticated cereals (such as wheat, barley, rye, oats, and sorghum) are consistently larger than those of their ancestral wild relatives (J. P. Harlan 1995, Fuller and Allaby 2009, Sakuma, Salomon and Komatsuda 2011). Larger seeds also result in larger endosperm (nutritional reserves in seeds) that tend to lead to for successful germination and establishment. For instance, (Kluyver, et al. 2013) proposed that ancient agricultural practices buried seeds quite deeply, leading to an increase in seed size under domestication so that seedlings would have the energy to grow out of the soil. Changes occurring during cereal domestication often result in more seeds, increased seed germination, and altered seed shape (Konishi, et al., 2006; Sakuma, Saloman, \& Komatsuda, 2011). Further, multivariate analysis could discriminate wild from cultivated grape (Vitis vinifera L.) seeds by seed shape (Terral, et al., 2010). Differences in shape may contribute to elevated germination in wild grape plants (Terral, et al., 2010). 
Domestication has improved the palatability of food since people do not like to be poisoned or injured by their food. For instance, wild potatoes (Solanum species) often have much higher levels of the toxin, solanine, than cultivated potatoes (McCollum \& Sinden, 1979). Cultivated forms of otherwise spiny species, like blackberries and dewberries (Rubus species), frequently have become spineless during domestication (Jennings, 1986). However, when fruits lose anti-herbivory mechanisms like spines, they may be less prone to dispersal. Domesticated carrot seeds had fewer spines with more brittle hooks and thus appear less adapted for distribution by attaching to fur of passing animals than the seeds of the wild plants (Small E. , 1978). Furthermore, there has been considerable research carried out comparing shifts in dispersal capabilities of caryopses (or specialized seeds of grasses) of domesticated cereals (such as wheat, barley, rye, oats, and sorghum) and their ancestral wild relatives (J. P. Harlan 1995, Fuller and Allaby 2009, Sakuma, Salomon and Komatsuda 2011). Cereal domestication often results in the loss of cellular features, prominent in their wild ancestors, that cause seeds to detach and scatter (i.e., the evolutionary loss of seed shattering; (Konishi, et al., 2006; Sakuma, Saloman, \& Komatsuda, 2011) ). In simple terms, the infructescence (seed-bearing branching system of the plant) breaks at certain points, distributing one or more seeds as a unit. The wild plants possess infructescences that shatter to scatter the seeds, while the infructescences of related cultivars remain intact, retaining the seeds (Fuller and Allaby, 2009). Further, the seeds of cultivated cottons (Gossypium species) remain attached for a considerable period on maternal plants, while seeds in the wild species drop individually and are freely scattered (Stephens, 1965).

Finally, seeds may evolve differences in their edibility, such that wild seeds tend to be less digestible whereas crop seeds tend to be easier to consume because they are more palatable 
or easier to break. Annual cotton cultivars have thin seed coats while the seeds of most of the wild species have hard, protective seed coats (Stephens, 1965).

\subsection{Crop Ferality}

Just as plant domestication often follows a predictable evolutionary path with a domestication syndrome, the evolution of crop ferality also can result the increased frequency of several key wild traits in plant populations derived from crops (Gressel, 2005). Crop ferality and volunteerism are well-known phenomena in agriculture (Ogg \& Parker, 1989; Gressel, 2005). Volunteer populations occur when unharvested seeds from a previous crop germinate and grow in and around agricultural fields. Volunteers are said to be plants that have developed from seed of a cultivated plant but not intentionally scattered. By colonizing field margins, home gardens, ditches, disturbed areas and other unmanaged habitats, feral plants can reproduce independently of the agricultural management upon which they depended as crop plants. Here, I explore the evolution of feral seed traits, that might contribute to the evolution of feral Cannabis (Cannabis sativa L.). Although some crop domestication traits may be lost during the evolution of feral populations, the process is not necessarily entirely reversed (Gressel, 2005) and thus my study will also contribute new knowledge to the fundamental understanding of key traits in the evolution of feral crops.

Weedy species are known to evolve rapidly in response to local selection pressures (Darwin C. , 1868; Darwin C. , 1859). The historical development of a recently revived hemp industry, particularly using plants that may possess significant levels of controlled substances, results in a large volume of seeds that can potentially seed volunteer and feral plant populations, similar to other species like sunflower and radish (Campbell \& Snow, 2009) and thus may create 
new environmental and crop - weed management risks in agricultural systems (Small E. , 1984; Gressel, 2005; Pilson \& Prendeville, 2004). Many cultivated plants have naturalized in introduced areas, sometimes becoming weedy or invasive (Sakai, et al., 2001). Infestations of feral rye (Secale cereale L.) in wheat fields in the western United States can reduce yield by $30-$ $70 \%$ and result in major economic losses annually (Pester, et al., 2000). Through better understanding of feral morphology, we may better anticipate and perhaps avoid this ecological and economic damage.

The extent to which cultivated plants can persist as feral populations is related to heritable variation in domestication traits, such as lack of seed dispersal or seed dormancy which may limit the plants' ability to persist as free-living populations. For example, canola, olive and many horticultural taxa are relatively undomesticated, and volunteer individuals can easily give rise to feral populations (de Caraffa, et al., 2002; Schafer, et al., 2011). In rice (Oryza sativa L.) only a few mutations are needed for the evolution of wild rice from crop plants (Chen, Lee, Song, Suh, \& Lu, 2004). Other crops such as maize and soybean are so strongly domesticated that their progeny rarely persist beyond first-generation volunteers (Gressel, 2005).

Herbivory is an important challenge to plant survival and reproduction, a challenge that may increase as a plant escapes from cultivated environments to grow in less managed landscapes. Plants respond to herbivory by evolutionary or plastic changes to their chemistry, morphology, phenology, and ecology (Edwards P. J., 1989; Herms \& Mattson, 1992; Edwards \& Crawley, 1999; Fine, Mesones, \& Coley, 2004), and can also lead to the evolution of defense traits. My research was motivated by the expectation that key insights into the evolution of ferality would be especially apparent by comparing feral plants with potential progenitor crop lineages. 
To avoid herbivory, plants express structural defenses that protect both vegetative and reproductive components. Seeds may represent one of the most vulnerable life-history stages of a plant life-cycle and thus their defense is essential to increasing parental fitness (Kolb, Ehrlén, \& Eriksson, 2007). Common seed defense mechanism protects seeds by reducing consumption from granivores and thus increasing the thickness and hardness of the pericarp. Moreover, seed colouration may be driven by seed predators searching and detecting bright seeds among the soil background. Thus, it would be an adaptive advantage for seeds to be camouflaged on soil surfaces with a cryptic patterns or darker colouration (Porter, 2013; Stevens, 2007). Notably, fibre and oi hemp seeds appear lighter than marijuana seeds and much lighter seeds than those from ruderal populations. Several observational studies document the persistence of feral populations of Cannabis in India, Nepal and eastern Europe (Hillig \& Mahlberg, 2004) but to my knowledge previous publications have not explored differences in seed morphology between populations. 


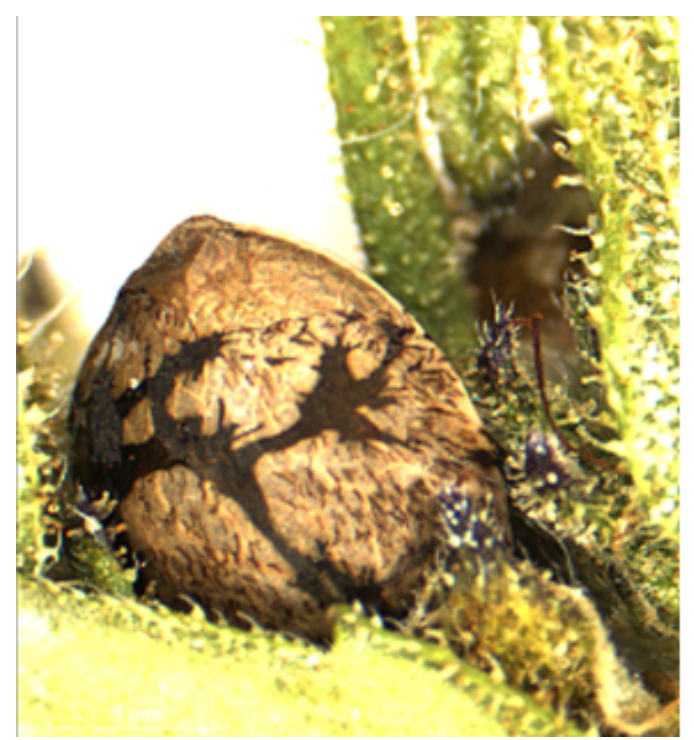

Figure 1.4 - Old hemp seed of UC-RGM. Seed still embedded in the flower (UC-RGM, Department of Agriculture, herbarium specimen) (photo taken by S. Naraine \& E. Small, 2014). Notice the dark patterning on the perianth coat.

\subsection{Thesis Objectives}

To identify features that differ between ruderal and domesticated plants I quantified achene characteristics of hemp, marijuana, or ruderal Cannabis populations. Specifically, I asked:

1. What are the morphological differences between:
a. north-temperate ruderal and domesticated achenes of Cannabis?
b. hemp and marijuana?
c. monoecious and dioecious hemp varieties?

2. Is pericarp thickness correlated to fracturing force?

Based on previous results (Small E. , 1974), I expected ruderal achenes would have more pronounced basal attenuation, smaller size, thicker pericarps, and darker coloration than domesticated varieties and predicted that a thicker pericarp would be more resistant to fracturing. 
While industrial production is rising in Canada, there are many sources, both illicit and feral populations that grow outdoors, ungoverned. These feral populations, that are generated by persistent volunteers derived from recent or historical agriculture activities, may required control both from a public health perspective as well as quality agricultural practice approach for industrial producers, if production were to move outdoors. One solution to this potential publish health risk is to understand the evolution of feral populations. By understanding what seed traits are adaptive and beneficial to the survival of feral populations, we can begin to identify traits that limit the spread of feral populations, therefore curtailing their survival in the environment. Why do you need to study differences among crop populations? 


\section{CHAPTER 2: MATERIALS \& METHODS}

To address my objective of measuring phenotypic characteristics of cannabis seeds, so I could determine whether these traits were sufficient to differentiate genotypes, I measured seed characteristics that are common differences in the domestication syndrome of other crops on a diversity of plant samples (Zohary, 2004); for example, the retention of mature seed on the mother plant has been noted in domesticated cereals such as wheat and barley (Harlan, de Wet, \& Price, 1973; Zohary, 1969). Of these characteristics, the most notable are the seed size, appearance, and durability (See Section 2.2).

\subsection{Tools Used in this Thesis}

\section{$\underline{\text { 2.1.1 Herbarium Specimens }}$}

The Herbarium of Agriculture and Agri-food Canada in Ottawa (DAO) contains the largest collection of C. sativa specimen vouchers, approximately 350 have been analysed for THC content (Small \& Beckstead, 1973). These vouchers have been used in studies over the last century (Small \& Cronquist, 1976; Small \& Beckstead, 1973; Small E. , 1974). Few herbaria in the world continue to preserve C. sativa vouchers, with some of the known collections such as Schultes Herbarium at Harvard University (USA), Vavilov Institute (Russia) and KEW Royal Botanical Gardens (England). Each of these have collections that are far less extensive than that of the DAO (Canada). The DAO contains hundreds of vouchers of $C$. sativa, whereas many of the others have $<100$ samples. In this study, we analysed only pistillate material (from both 
monoecious and dioecious) that contained mature achenes. Of the 100 vouchers examined, there were 34 hemp samples (11 fibre and 23 oilseed), 30 marijuana and 30 ruderal specimens.

\subsubsection{Specimens Examined}

Table 2.1 presents information on collectors and DAO accession numbers, and cultivar names for the 100 vouchers examined. Only pistillate material (whether monoecious or dioecious), with mature achenes, was considered in this study. The hemp cultigen was represented by 11 dioecious fibre cultivars. The oilseed cultigen was represented by 13 dioecious and 10 monoecious cultivars. The marijuana cultigen was represented by 30 strains. Ruderal plants were represented by 30 collections from temperate areas of the world. All of the ruderal, fibre and oilseed collections were known to possess low THC content (where low was considered to be $<0.3 \% \mathrm{w} / \mathrm{w}$ ), whereas all of the marijuana collections were known to exhibit high THC content (where high THC was considered to be $>0.3 \% \mathrm{w} / \mathrm{w}$ ). Six high-THC ruderal populations from India were also examined (these are classifiable as $C$. sativa subsp. indica var. kafiristanica (Vavilov) E. Small and Cronquist (Small \& Cronquist, 1976), Figure 2.1) but the sample size was considered too small to include in the statistical analyses. 


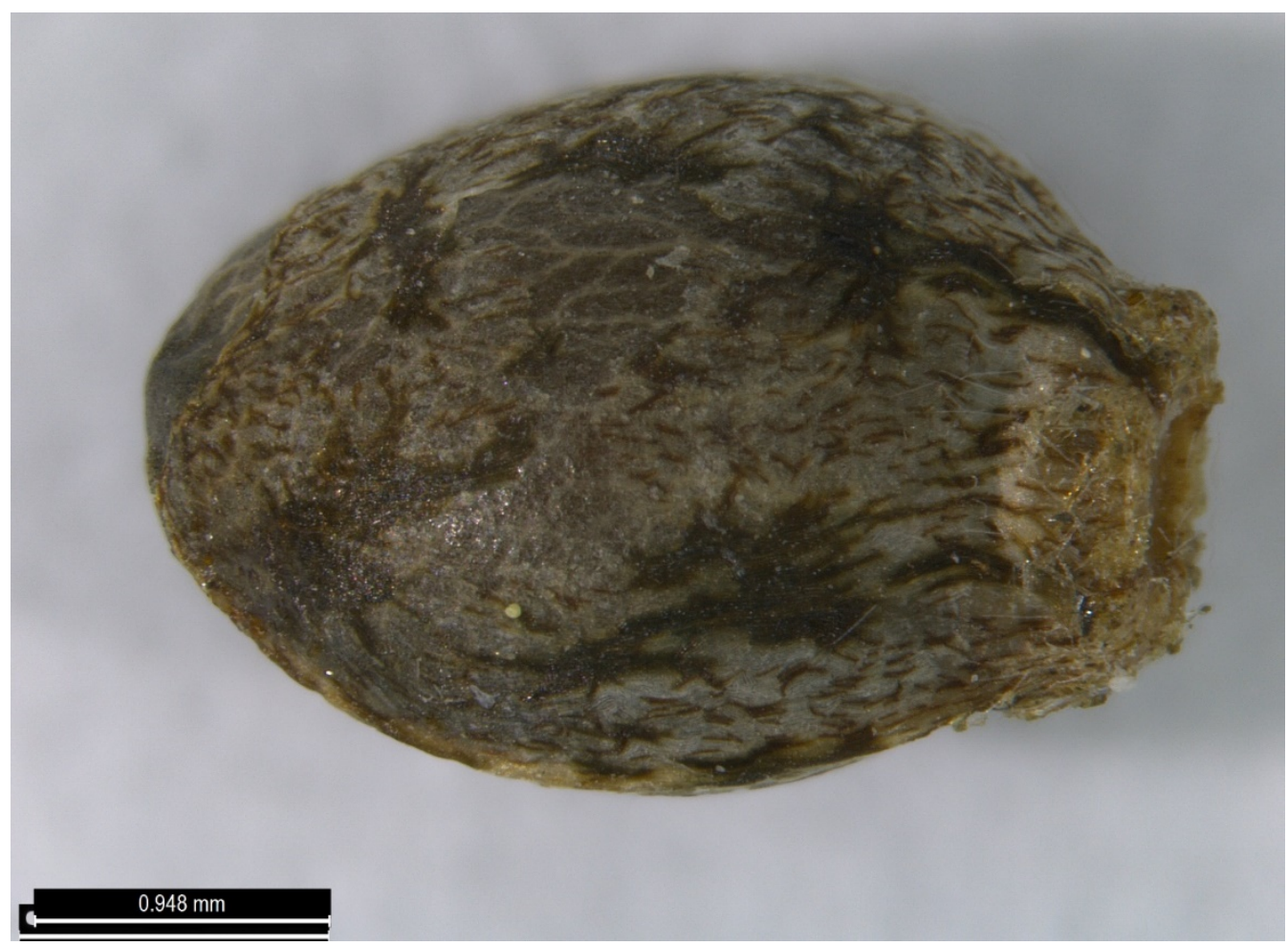

Figure 2.1 - Representative example of 'kafiristanica' (Cannabis sativa subsp. indica var. kafiristanica)

'Kafiristanica' seeds are a high-THC "wild" variety of the subspecies indica. They are small and display marbled perianth and an attenuated base.

Table 2.3 - Collectors and DAO accession numbers, and cultivar names (where available).

FIBRE CULTIVARS (all collected by E. Small): 132157 (Lovrin 53-65), 132162, 132163

(Tiborszallasi), 132167 (LKCSD), 135048 (Llonspdiske), 135049 (Fibrimon Truh), 135050

(Fibrimon Mittelspat), 135051 (Fibrimon Spat Eliten), 135110, 135114 (Rastislavicke), 135129

(Fibramulta 151) (All specimens were grown in a common garden in 1971 in Ottawa, as reported in Small and Beckstead 1973, and all possessed low levels of THC, $<0.3 \%$.).

OILSEED CUlTIVARS: The 13 dioecious collections included 886530 (ESTA-1), 886532

(Victoria), 886535 (Petera), 886540 (Finola), 886541 (Georgina), 886542 (Heidron), 886543 
(Hempnut), 886545 (Crag), 886546 (CFX-2), 886547 (CFX-1), 886548 (CanMa), 886551 (ARCExpress), 886553 (CRS-1). The 10 monoecious cultivars included 886531 (Yvonne), 886533 (UC-RGM), 886534 (Silesia), 886536 (Jutta), 886537 (Joey), 886538 (Ida), 886539 (Debbie), 886544 (Delores), 886550 (Canda), 886552 (Alyssa, female predominant) (The 23 oilseed cultivars were grown in a common garden in Ottawa in 2013 and were collected by E. Small and A. Ward. All were grown from pedigreed breeder's seed. All were intended for sale in Canada for harvest of seed, and as required by law, all have proven to have very low levels of THC, $<0.3 \%$ )

LOW-THC RUDERAL COLLECTIONS: The 30 north-temperate, low-THC ruderal collections included the following 17 vouchers: 131712, 131715, 131720, 131815, 131816, 131825, 131838, $131848,131850,132159,132179,132186,132193,132214,132228,132250,135068$ (These were planted in a common garden in Ottawa in 1971 from seeds obtained from ruderal populations in North America and Europe, as reported in Small and Beckstead [1973]). Also examined were the following 13 accessions collected directly from various ruderal locations in North America in the middle of the $20^{\text {th }}$ century: $158369,743592,743593,743597,743870$, 743896, 743923, 743932, 743933, 743934, 743944, 743974, 743975.

High-THC RUDERAL COLLECTIONS: 131727, 131790, 131792, 131797, 131805, 656599 (These seeds were collected from India by E. Small and were grown in a common garden Ottawa in 1971 and collected by E. Small). 
MARIJUANA STRAINS: The 30 marijuana accessions used included 25 vouchers at DAO grown in Ottawa in 1971, or 1973 and collected by E. Small: 131269, 131272, 131274, 131276, 131278, 131280, 131281, 131725, 131726, 131728, 131783, 131793, 131796, 131801, 131802, 131804, 131810, 131814, 131818, 131829, 131834. 131835, 131842, 131851, 132168. Also included were the following collected by S. Naraine in 2016: 1 (Biddy Early), 2 (Black Indica), 3 (Blueberry), 4 (Green Crack), 5 (Strawberry Skunk).

\subsection{Data Collection}

Ninety-four specimens were evaluated for the following nine seed characteristics, based on two to four representative, mature achenes. The six high-THC ruderal collections from India were examined only for three characters, to avoid damage to these rare collections. The lowTHC accessions were adapted to north-temperate region photoperiods and produce flowers and fruits in the autumn as a result of shortening day length. By contrast, the high-THC accessions (both ruderal and domesticated) were adapted to subtropical region photoperiods, and so when grown in the short season of Ottawa, Canada, flowering and fruiting could not occur before a killing frost. Accordingly, samples of the original achenes (which are preserved on the herbarium vouchers) were examined.

\subsubsection{Seed Dimensions}

The seeds of C. sativa are oblate (flattened) ellipsoid. For this study, the three maximum axes are interpreted as "length", "width" and "thickness" (Figure 2.2). Length and width were 
measured using a calibrated graduated ocular lens (accurate to $0.1 \mathrm{~mm}$ ) of a Leica MZ125 stereoscope. Thickness was measured with a gauge accurate to $0.01 \mathrm{~mm}$ (STM model 200-675).

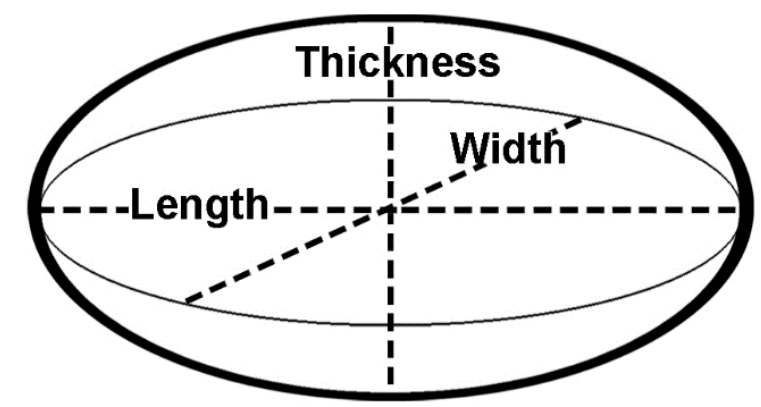

Figure 2.2 - Shape of an achene of Cannabis sativa, showing dimensions measured.

\subsubsection{Seed Mass}

The weight each seed was determined using a digital balance (Mettler Toledo AG285, accurate to $0.0001 \mathrm{~g}$ ), 2-4 seeds per sample were averaged to obtain the 1000 seed weight basis.

\subsubsection{Perianth adherence}

Pistillate flowers of C. sativa, unlike the staminate flowers, do not develop tepals. Instead, tissue homologous with the perianth envelops the achene. This perianth tissue is mottled, and adheres, to different degrees, to the pericarp, often showing regions of adherence beside regions where the tissue has sloughed off, evidenced by the strongly veined appearance of the underlying pericarp (Figure 2.3) (E. Small, Personal Communication, 2015). The percentage (in increments of $5 \%$ ) of perianth cover was estimated by viewing under a dissecting microscope (Leica MZ-12.5) (Figure 2.3). 


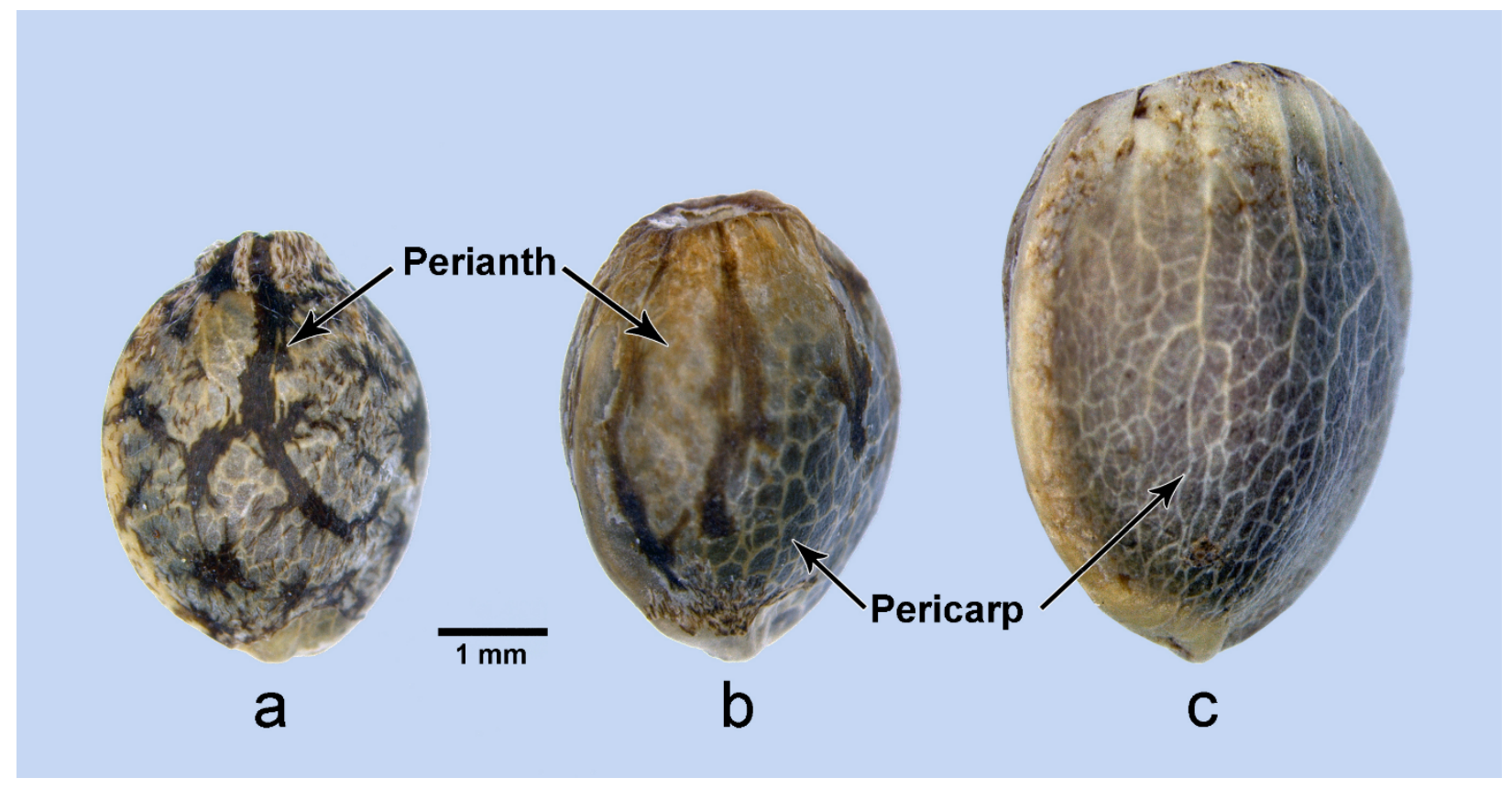

Figure 2.3 - Achenes of Cannabis sativa, showing variation in perianth adherence.

(a) Ruderal achene with almost complete adherence. (b) Marijuana achene with about $70 \%$ adherence. (c) Fibre hemp with the entire perianth sloughed off to reveal the veined pericarp.

\subsubsection{Pericarp shade}

Achene pericarps vary considerably in shade (Figure 2.4). The relative darkness of the pericarp was measured by determining the grayness (in 256-bit grayscale) of a photograph of a $1 \mathrm{~mm}^{2}$ perianth-free portion of an achene. The perianth was too extensive and adherent to 14 ruderal, 3 oilseed, 1 fibre, and 2 marijuana accessions to measure this feature. Photography was conducted using a Leica M205C microscope equipped with a camera (Leica model DFC420). Image analysis software (MATLAB v. 2016b), was employed to determine the average grayscale (Appendix I). 

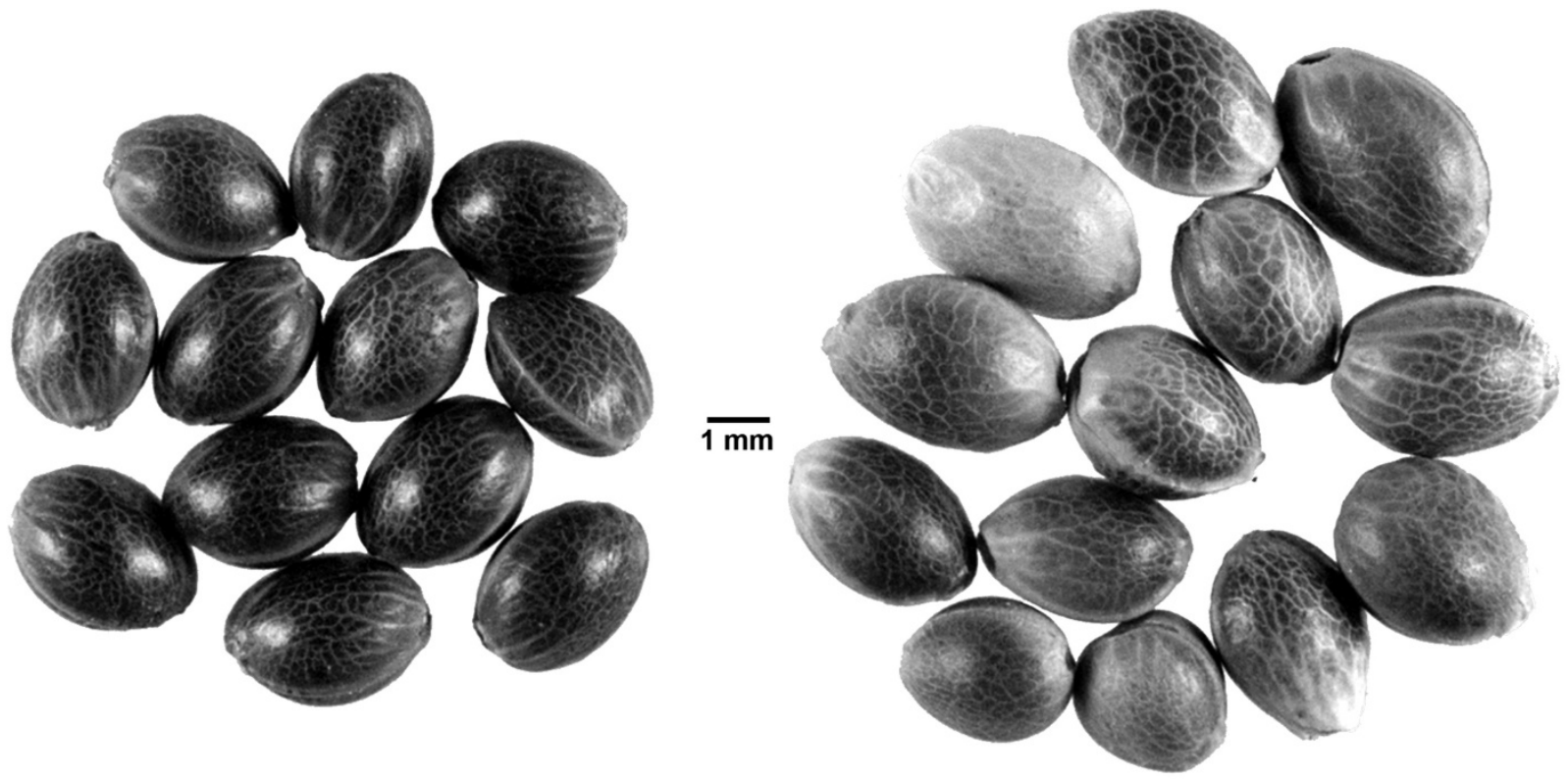

Figure 2.4 - Comparison of pericarp darkness in achenes domesticated for hemp and for marijuana.

Left: dark domesticated achenes of a form of marijuana. Right: Achene of a fibre cultivar. Note that a perianth layer is not present in these achenes, so that the pericarp is exposed.

\subsubsection{Resistance to Pericarp Fracturing}

Because birds must crush the seed to access nutrients inside, a force meter with the ability to measure the compressive stress is a useful tool when accessing seed traits. Thus, the resistance to fracturing of the pericarp can quantify a seed's susceptibility to predation. The pericarp's resistance to fracturing can be measured using a dual-range force sensor mounted to a height gauge (Figure 2.6a). The height gauge shown in figure 2.6b, is a single column, but I chose to use a dual column for more stability along the y-axis. The model of height gauge was an STM model\# 200-675 which is a digital version that has a manual lever that regulates the z-axis ('up' and 'down'). The force meter was a dual-range (either $\pm 10 \mathrm{~N}$ or $\pm 50 \mathrm{~N}$ ) force sensor by Vernier. This sensor is specific to $0.05 \mathrm{~N}$ when in the $10 \mathrm{~N}$ range and coupled with Logger Pro 7 software. The mounts for the force meter on to the lower face of measuring jaw on the height gauge, as 
well as the extended base with seed platform were custom machined and built by Mike Neiser of STUMARK machining Inc., Guelph, Canada.

Resistance to pericarp fracturing was measured by constructing an apparatus to measure the compressive force required to fracture the achene. This instrument (Figure 2.7) coupled a Vernier dual-range force sensor (accurate to 0.05 Newtons, maximum range of 50 Newtons), with a height gauge (STM model 200-675). A single seed from each voucher was fractured. Using Logger Pro 7 software (which plots the force 100 times/second), the resulting graph was then analysed for its peak force needed to fracture the pericarp.
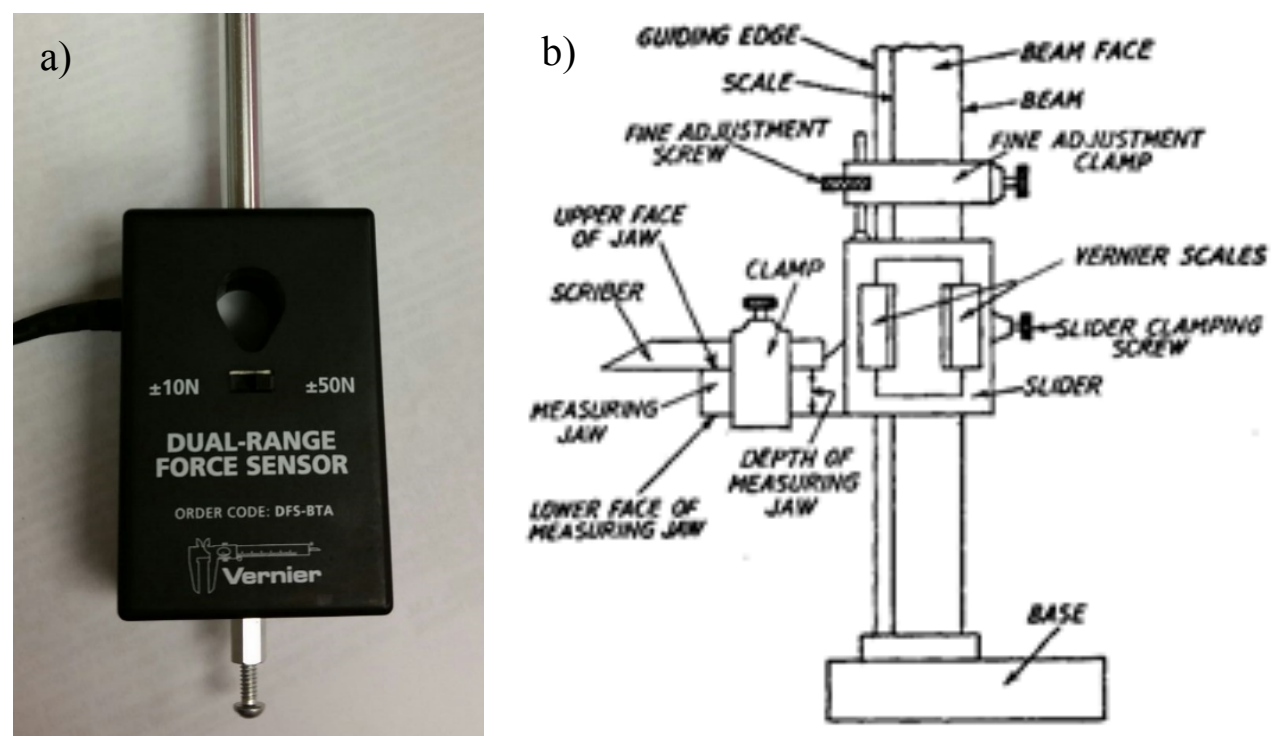

Figure 2.5 - Tool to measure the force needed to crack a seed a) Dual-range force sensor by Vernier. b) Schematic of a single column height gauge. The dualrange force sensor by Vernier (left) was mounted to the lower face of the measuring jaw on the height gauge (right). Built by M. Neiser (Stumark Machining Inc., Guelph). 


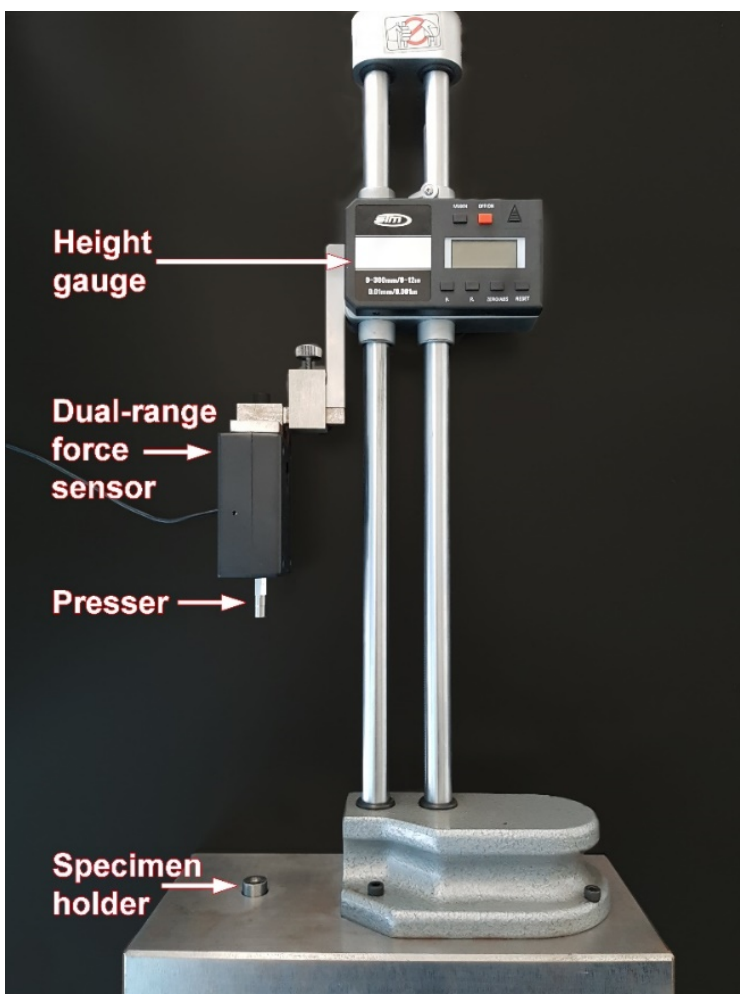

Figure 2.6 - Force press to measure resistance to pericarp fracturing

\subsubsection{Attenuation of Base}

Attenuation of the achene base was assessed employing the ordered multistate character scoring described in Small (1974). This method involves setting classes of attenuation (4 classes), as I did in Figure 2.7, and assigning each seed to a class based on observation. 


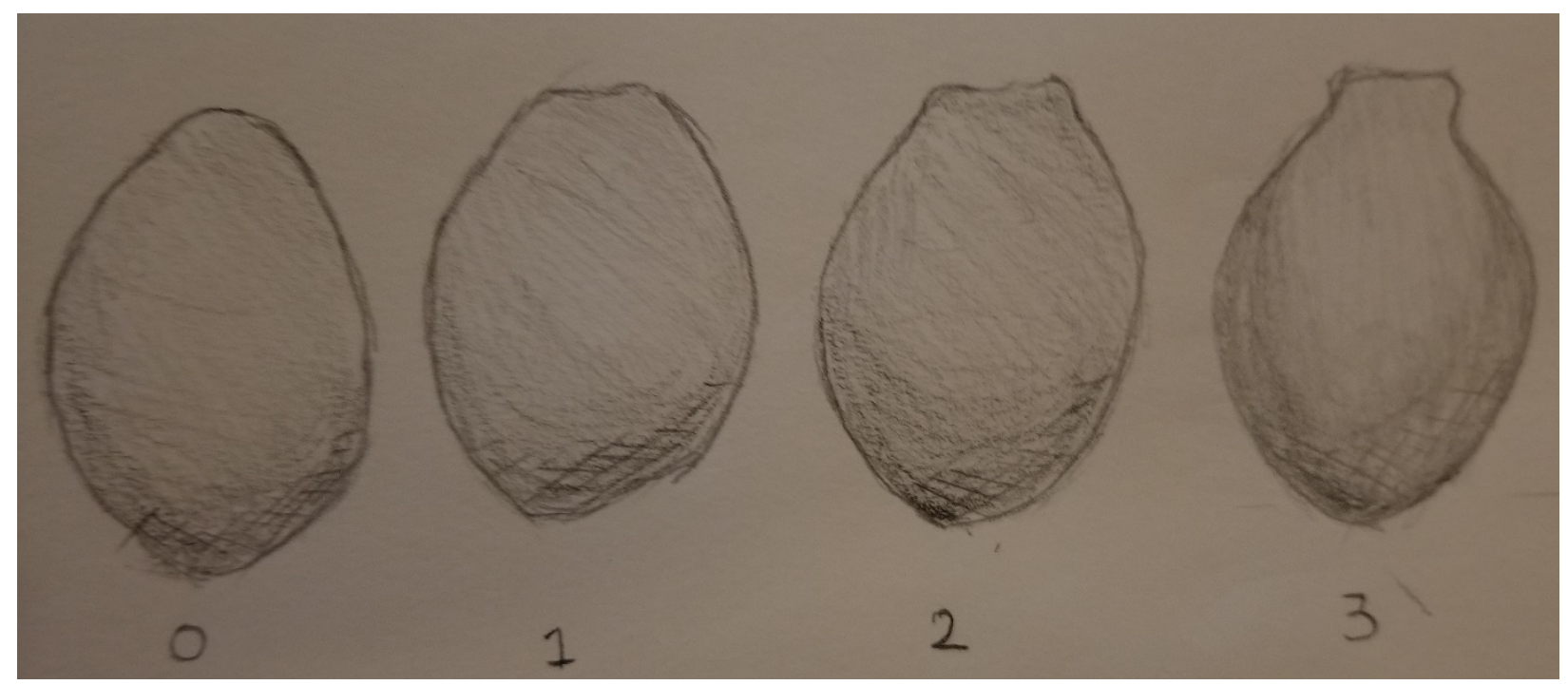

Figure 2.7 - Outlines of achenes of Cannabis sativa, showing scoring of basal attenuation The biometric index of scoring basal attenuation was performed in a scale of $0-3$ where 0 - is the roundest and 3 - is representative of the most attenuated.

\subsubsection{Pericarp Thickness}

The thickness of the pericarp was measured, post-fracturing (2.2.5 Resistance to Pericarp Fracturing), using an electronic caliper (accurate to $0.01 \mathrm{~mm}$ ).

\subsection{Statistical Analysis}

To test for differences in achene morphology among the three genotypes (hemp, including oilseed and fibre classes; marijuana; and north-temperate ruderal; kafiristanica was excluded due to sampling limitations), I used an ANOVA which included group as a fixed-effect factor. To determine significant pair-wise differences, I ran post-hoc, Tukey, multiplecomparisons-of-means tests. To test for differences in achene morphology among monoecious oilseed, dioecious oilseed, and dioecious fibre hemp samples, I used a linear ANOVA which included group as a fixed-effect factor. 


\section{CHAPTER 3: RESULTS}

\subsection{Differences Between Domesticated (Hemp and Marijuana) and North-Temperate, Low-THC Ruderal Plants}

Seed morphology differed significantly among genotypes for all seed traits $(\mathrm{P}<0.001$, ANOVA presented in Table 3.1). Domesticated seeds were (11\%, 17.9\%, and 19\% longer, wider and taller and 1.7 times heavier than the seeds of the ruderal, spontaneae, plants measured.

Ruderal seeds were 17 shades darker (on a 256-point greyscale) with 50.5\% more perianth coverage than crop cultivars. The domesticates have $20 \%$ thicker pericarps and can withstand $20.4 \%$ more force than spontaneae (Table $3.1 \mathrm{~b}$ ).

Table 3.1a - One-way ANOVA of the three genotypes (hemp, grouping oilseed and fibre classes; marijuana; and north-temperate ruderal) with post-hoc Tukey-Kramer comparison.

\begin{tabular}{|l|l|l|l|l|l|l|l|}
\hline & F-value & P-value & Ruderal & Hemp & Marijuana & Min & Max \\
\hline $\begin{array}{l}1000 \text { Seed mass } \\
(\mathrm{g} / 1000 \text { seeds })\end{array}$ & 47.55 & $<0.0001$ & $9.55 \pm 2.78^{\mathrm{A}}$ & $19.14 \pm 4.98^{\mathrm{B}}$ & $13.27 \pm 3.53^{\mathrm{C}}$ & 4.17 & 31.07 \\
\hline Length $(\mathrm{mm})$ & 119.98 & $<0.0001$ & $3.67 \pm 0.30^{\mathrm{C}}$ & $4.73 \pm 0.46^{\mathrm{B}}$ & $3.52 \pm 0.32^{\mathrm{A}}$ & 2.75 & 5.75 \\
\hline Width $(\mathrm{mm})$ & 62.58 & $<0.0001$ & $2.59 \pm 0.22^{\mathrm{A}}$ & $3.37 \pm 0.33^{\mathrm{B}}$ & $2.94 \pm 0.29^{\mathrm{C}}$ & 2.10 & 4.01 \\
\hline Height $(\mathrm{mm})$ & 49.32 & $<0.0001$ & $2.21 \pm 0.24^{\mathrm{A}}$ & $2.90 \pm 0.30^{\mathrm{B}}$ & $2.56 \pm 0.27^{\mathrm{C}}$ & 1.79 & 3.48 \\
\hline $\begin{array}{l}\text { Perianth } \\
\text { Adherence }\end{array}$ & 47.39 & $<0.0001$ & $68 \% \pm 2 \%^{\mathrm{A}}$ & $20 \% \pm 24 \%{ }^{\mathrm{B}}$ & $15 \% \pm 19 \%^{\mathrm{B}}$ & $0 \%$ & $99 \%$ \\
\hline Elongated Base & 53.93 & $<0.0001$ & $2.0 \pm 0.8^{\mathrm{A}}$ & $0.4 \pm 0.6^{\mathrm{B}}$ & $0.6 \pm 0.6^{\mathrm{B}}$ & 0 & 3 \\
\hline $\begin{array}{l}\text { Pericarp } \\
\text { Thickness }\end{array}$ & & 0.0006 & $0.14 \pm 0.02^{\mathrm{B}}$ & $0.17 \pm 0.04^{\mathrm{A}, \mathrm{B}}$ & $0.18 \pm 0.05^{\mathrm{A}}$ & 0.08 & 0.26 \\
\hline Fracturing Force & 10.40 & 0.0002 & $20.2 \pm 4.7^{\mathrm{B}}$ & $27.4 \pm 7.8^{\mathrm{A}}$ & $23.4 \pm 6.5^{\mathrm{B}}$ & 8.48 & 38.61 \\
\hline Pericarp Shade & & $<0.0001$ & $68.71 \pm 7.72^{\mathrm{A}}$ & $101.82 \pm 15.81^{\mathrm{B}}$ & $69.91 \pm 13.0^{\mathrm{A}}$ & 43.02 & 134.05 \\
\hline
\end{tabular}

Table 3.1b - Comparison of Pericarp Thickness and Shade

\begin{tabular}{|l|l|l|l|l|l|l|}
\hline & P-value & Ruderal & Hemp & Marijuana & Min & Max \\
\hline Pericarp Thickness & 0.0006 & $0.14 \pm 0.02^{\mathrm{B}}$ & $0.17 \pm 0.04^{\mathrm{A}, \mathrm{B}}$ & $0.18 \pm 0.05^{\mathrm{A}}$ & 0.08 & 0.26 \\
\hline Pericarp Shade & $<0.0001$ & $68.71 \pm 7.72^{\mathrm{A}}$ & $101.82 \pm 15.81^{\mathrm{B}}$ & $69.91 \pm 13.0^{\mathrm{A}}$ & 43.02 & 134.05 \\
\hline
\end{tabular}




\subsection{Differences Between Hemp and Marijuana Genotypes}

Marijuana and hemp (fibre and oilseed collectively) plants differed significantly for six of the nine measured characters (weight, length, width, thickness, fracturing force and pericarp shade; Table 3.1). Marijuana was 32 shades darker than hemp. Hemp was $44 \%$ heavier, $25 \%$ longer, $12.8 \%$ wider, and $11 \%$ taller than marijuana; overall, hemp seeds are larger than marijuana seeds. Hemp seeds also had a 5\% thicker pericarp and were $14.6 \%$ more resistant to fracturing than marijuana seeds. There was no significant difference between domesticated hemp and marijuana seeds with respect to perianth adherence or basal attenuation.

\subsection{Differences Among Dioecious Fibre, Dioecious Oilseed, and Monecious Oilseed Genotypes}

Our analyses detected fewer significant morphological differences among dioecious fibre, dioecious oilseed, and monoecious oilseed achenes (Table 3.2). Dioecious fibre hemp plants possessed seeds that were $14 \%$ longer than dioecious oilseed hemp which, in turn, was $6 \%$ longer than monoecious oilseed hemp samples. Furthermore, basal elongation was 5.3 times more prominent in monoecious hemp samples than dioecious hemp samples. All other morphological features did not differ among genotypes. 
Table 4.2 - One-way ANOVA of three hemp genotypes (dioecious fibre, dioecious oilseed and monoecious oilseed) with post-hoc Tukey-Kramer comparison.

\begin{tabular}{|l|l|l|l|l|l|}
\hline & F-value & P-value & Fiber & Oilseed & \\
\hline & & & Dioecious & Dioecious & Monoecious \\
\hline 1000 Seed mass (g/1000 seeds) & 2.00 & 0.15 & $21.60 \pm 4.51$ & $18.57 \pm 5.17$ & $17.44 \pm 4.67$ \\
\hline Length $(\mathrm{mm})$ & 1.55 & 0.23 & $4.90 \pm 0.38$ & $4.58 \pm 0.43$ & $4.78 \pm 0.52$ \\
\hline Width $(\mathrm{mm})$ & 4.24 & 0.02 & $3.57 \pm 0.17$ & $3.35 \pm 0.33$ & $3.18 \pm 0.35$ \\
\hline Height $(\mathrm{mm})$ & 1.35 & 0.28 & $2.96 \pm 0.20$ & $2.94 \pm 0.33$ & $2.77 \pm 0.33$ \\
\hline Perianth Adherence & 2.00 & 0.15 & $0.07 \pm 0.08$ & $0.24 \pm 0.32$ & $0.26 \pm 0.16$ \\
\hline Elongated Base & 10.2 & 0.0004 & $0.05 \pm 0.11$ & $0.32 \pm 0.45$ & $0.98 \pm 0.68$ \\
\hline Pericarp Thickness & 1.66 & 0.21 & $0.15 \pm 0.03$ & $0.18 \pm 0.03$ & $0.17 \pm 0.04$ \\
\hline Fracturing Force & 1.03 & 0.37 & $24.75 \pm 7.29$ & $29.35 \pm 7.54$ & $27.26 \pm 8.46$ \\
\hline Pericarp Shade & 1.94 & 0.16 & $110.16 \pm 18.59$ & $98.96 \pm 13.02$ & $97.29 \pm 14.62$ \\
\hline
\end{tabular}

\subsection{Fracture Resistance in Relation to Pericarp Thickness}

Hemp genotypes required $7.2 \mathrm{~N}(26.2 \%)$ and $4 \mathrm{~N}(14.6 \%)$ greater force to fracture the pericarp relative to ruderal and marijuana plants, respectively (Table 3.1). Furthermore, both hemp and marijuana genotypes had thicker pericarps than ruderal plant samples (Table 3.1b). Across all plant samples, the force required to fracture the achenes increased proportionately to pericarp thickness $\left(\mathrm{R}^{2}=0.4584\right)$ (Figure 3.1). 


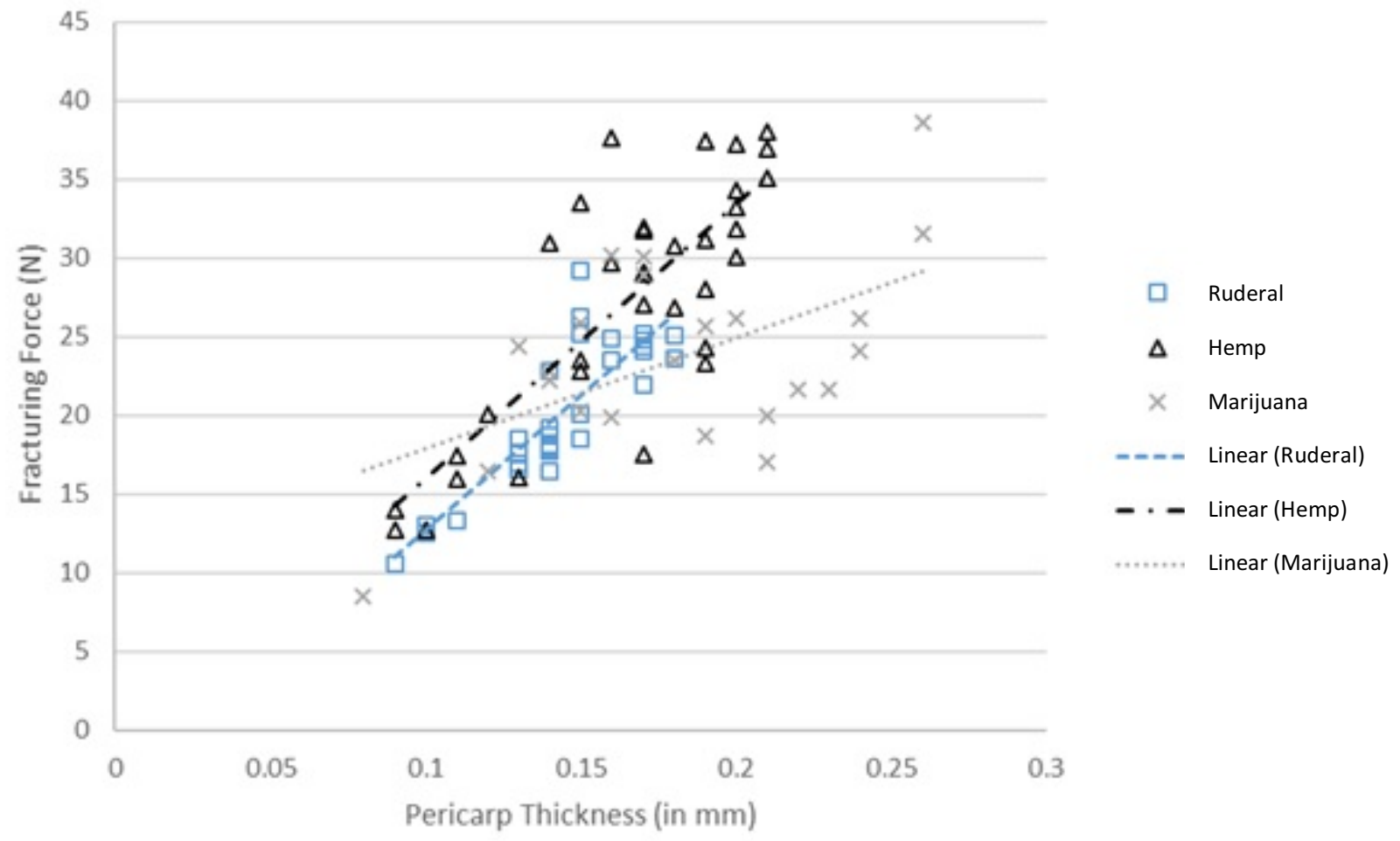

Figure 3.1 - The relationship between pericarp thickness to fracturing force. 


\section{CHAPTER 4: DISCUSSION \& CONCLUSIONS}

This study identified achene characteristics that consistently differed between the following C. sativa genotypes: (1) north-temperate ruderal vs. domesticated, (2) Marijuana (high-THC) genotypes vs. "hemp" (low-THC fibre and oilseed collectively), and (3) Fibre vs. oilseed hemp. Below, these differences are summarized, and considered.

For each of the four group comparisons (Figure 1.1), there were nine traits measured that were broadly categorized as features distinguishing size, camouflage, disarticulation and seed durability (Table 4.1). Seed size is a trade-off between producing few large seeds that can survive longer without germinating or many smaller seeds where many will not survive to germination (Sadras, 2006). I expected, in agricultural populations to see larger seeds that remained on the flower and that were easier to fracture due to the necessity to harvest and dehull. Camouflage may allow seeds to evade bird predation and thus may be more pronounced in ruderal populations. Disarticulation of achenes from inflorescences helps humans harvesting seeds and thus is favoured in crop populations. I prediced that the ability of seeds to withstand fracturing would be beneficial in non-agricultural environments, but the trait should be lost in crop populations. 
Table 4.1 - Characteristic Traits of a Domestication Syndrome.

\begin{tabular}{|c|c|c|}
\hline Character & Measure & Adaptive Rationale \\
\hline \multirow[t]{4}{*}{ Size } & Length & \multirow{4}{*}{$\begin{array}{l}\text { Domestication often results in selection for larger seeds and more seeds } \\
\text { (Sadras, 2006). }\end{array}$} \\
\hline & Width & \\
\hline & Thickness & \\
\hline & Mass & \\
\hline \multirow[t]{2}{*}{ Camouflage } & Perianth & $\begin{array}{l}\text { Retention of perianth to the pericarp, is a mode of camouflage known } \\
\text { as disruptive colouration (Stevens \& Merilaita, 2009). Disruptive } \\
\text { coloration due to the high contrast of the patterning it effectively } \\
\text { breaks up outlines making it more difficult for herbivores to see seeds } \\
\text { on complex backgrounds (Porter, 2013). }\end{array}$ \\
\hline & Pericarp & $\begin{array}{l}\text { Darker shades of pericarps in ruderal populations may more closely } \\
\text { match the colour of the soil (Porter, 2013). }\end{array}$ \\
\hline Disarticulation & $\begin{array}{l}\text { Achene } \\
\text { Base Shape }\end{array}$ & $\begin{array}{l}\text { In nature, disarticulating mature seed occurs by the development of an } \\
\text { abscission zone at an attenuated base of the achene. Domestication } \\
\text { tends to result in the loss of the attenuated seed base and thus loss of } \\
\text { dispersal (Fuller \& Allaby, 2009). }\end{array}$ \\
\hline \multirow[t]{2}{*}{$\begin{array}{l}\text { Seed } \\
\text { durability }\end{array}$} & $\begin{array}{l}\text { Fracturing } \\
\text { Force }\end{array}$ & $\begin{array}{l}\text { Achenes in the wild may be selected for withstanding crushing forces } \\
\text { as a mechanical protection from herbivory (Lucas, Peters, \& Arrandale, } \\
\text { 1994). }\end{array}$ \\
\hline & $\begin{array}{l}\text { Pericarp } \\
\text { Thickness }\end{array}$ & $\begin{array}{l}\text { My original prediction was that thicker pericarps provided additional } \\
\text { protection for the developing embryo (Garcia-Lara, et al., 2004). }\end{array}$ \\
\hline
\end{tabular}

\subsection{Cannabis Crop Seeds are Larger than Ruderal Seeds}

Compared with ruderal plants, the achenes of domesticated genotypes tended to be larger and heavier: hemp (fibre and oilseed cultivars collectively) were 50.1\% heavier; marijuana achenes were $28 \%$ heavier than the ruderal achenes (Table 3.1). When maternal plants produce heavier seeds, they create offspring that possess more seedling food reserves, enabling offspring to quickly establish leaves, thus initiating photosynthesis as soon as possible and providing offspring with a significant competitive advantage (Hicks \& Dabney, 1897; Salisbury, 1942; Black, 1958). Artificial selection has emphasized this trait in crops to both promote aboveground biomass yield and, perhaps secondarily, for increased food value of achenes. In contrast, 
weed species often produce many poorly provisioned offspring because they commonly grow in environments where their lifespan is unpredictable or often short (r-selection) (Pianka, 1970). Ruderal C. sativa, like many weedy annual plants, has clearly adopted this strategy, in minimizing allocation of resources to the reproductive bodies (achenes). An alternative explanation of larger propagule size in domesticated plants relative to their wild relatives was offered by (Kluyver, Charles, Jones, Rees, \& Osborne, 2013), who proposed that ancient agriculturalists buried seeds quite deeply to protect them against herbivores. They hypothesized that this led to an increase in seed size so that seedlings would have the energy to grow out of the soil. Both hypotheses remain untested in Cannabis.

Compared with ruderal plants, the achenes of domesticated crops tended to lack an attenuated base (Figure 4.1). Small (1974) found that an attenuated base in ruderal seeds was closely correlated with a well-developed abscission zone which facilitates disarticulation as soon as the fruits are ripe. This may minimize the period that they are susceptible to predation by birds, which I suspect tend to consume seeds from the inflorescences because they are more obvious when attached to the plant, rather than on the ground. The lack of an attenuated base in domesticated achenes and the corresponding tendency of the achenes to remain on the plant at maturity facilitates grain harvest. This retention of propagules is the most important way that humans have domesticated the majority of grain crops (Harlan, 1995) (Fuller \& Allaby, 2009) (Sakuma, Salomon, \& Komatsuda, 2011). Thus, basal attenuation may be the trait that most closely predicts shattering in C. sativa, an important trait during the process of domestication. 


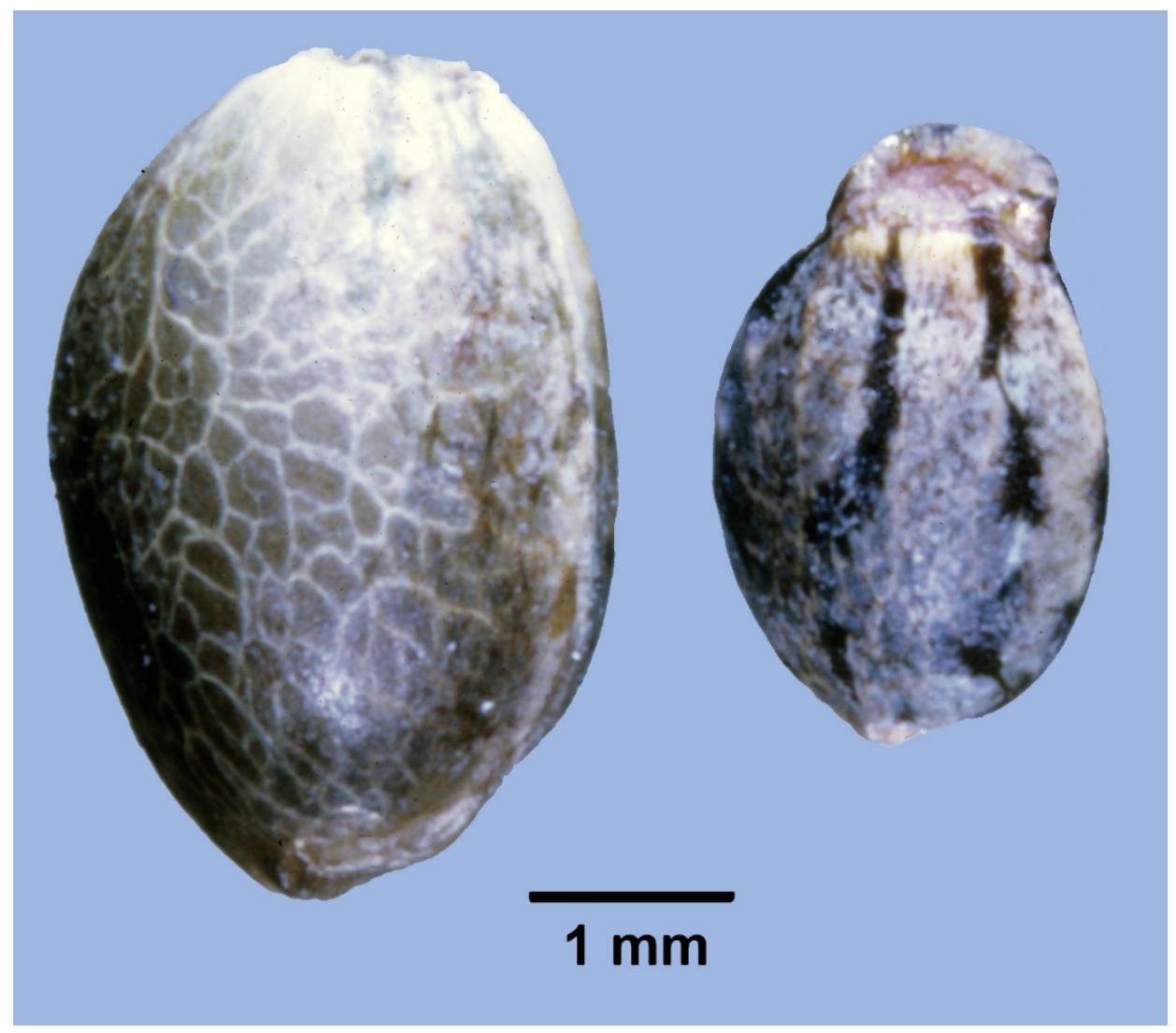

Figure 4.1 - Domesticated and ruderal achene of Cannabis sativa compared A domesticated (left) and ruderal (right) achene of Cannabis sativa. Note that the domesticated fruit is larger, lacks a camouflagic persistent covering layer derived from the perianth, and lacks an attenuated attachment base and thus reduces the rate of disarticulation in the ruderal form.

The achenes of domesticated $C$. sativa tended to be less than $20 \%$ covered by a tightly adhering mottled layer homologous with the perianth, while the ruderal plants were about 70\% covered. I predict this layer acts to disruptively camouflage offspring, hiding the fallen achenes from mammalian and insect herbivores, although this remains to be tested. Seeds that are difficult to distinguish from the soil on which they have fallen are much more likely to survive (Porter, 2013). Janischevsky (1924), working on the ecology of ruderal Russian hemp, noted that birds are very infrequently seen on the ground in pursuit of fallen seeds of $C$. sativa. By contrast, the achenes of domesticated plants mostly remain on the plant, and birds perch on the infructescences (i.e., the floral architecture that holds the developing fruits) gorging on the seeds. 
Moreover, I noticed while working on this project that, in domesticated Cannabis sativa, the camouflagic perianth attached to the pericarp tends to slough off, perhaps because it does not provide camouflage on the plant (Figure 2.3). In summary, achenes from domesticated and ruderal C. sativa differ in size, shape and colour, likely as a result of divergent selection in crop and ruderal environments (Figure 4.1).

\subsection{Marijuana Seeds are Smaller and Lighter than Hemp Seeds}

Achenes of marijuana were smaller and weighed less than those of hemp (Table 3.1a). Moreover, the most notable difference between these two genotypes was pericarp shade. Marijuana achenes tended to express a darker pericarp shade than hemp achenes (about 70\% blacker on average; Figure 2.4). The presence of relatively light-colored achenes in hemp cultivars has been recorded by (Vavilov, 1931), (Serebriakova \& Sizov, 1940), and (Clarke \& Merlin, 2013). Humans have a preference for lighter-colored edible seeds (e.g., sunflowers, (Small, 2016)). Since hemp seeds are more likely to be consumed than marijuana seeds and since C. sativa has been more intensively domesticated for hemp than for marijuana, we suspect the difference in shade may simply reflect this evolutionary history.

\subsection{Fibre Hemp Seeds are Heavier than Oilseed Hemp Seeds}

Until the last decade, most hemp was cultivated for stem fibre, and oilseed usage was quite limited (Small, 2016). Recently, oilseed has become the more economically important product, although there are still far more fibre cultivars available than oilseed cultivars. Perhaps predictably based on their history of selection for fibre versus seed characteristics, achenes of fibre cultivars proved to be heavier (21.3\% on average; Table 3.2$)$ than the achenes of oilseed 
cultivars. Perhaps this result is because fibre varieties tend to produce far fewer seeds than oilseed varieties (Small, 2016), and thus the seeds are better provisioned and larger. However, these differences may simply reflect a life-history trade-off and not the potential for oilseed cultivars to produce larger seeds if they experience artificial selection for large seed size. Specifically, (Clarke \& Merlin, 2013) described some Chinese oilseed biotypes grown for eating out of hand which are especially large. However, it appears that a larger yield of achenes rather than larger achenes is the principal criterion that has been employed to date to select oilseed cultivars (Small, 2016).

\subsection{Dioecious Genotypes Produce Heavier Seeds than Monoecious Genotypes}

Achenes of dioecious oilseed cultivars were heavier ( $9.9 \%$ on average; Table 3.2$)$ than the achenes of monoecious oilseed cultivars. This difference may reflect a variety of evolutionary processes that are occurring, and our results point to the need for more research in the field. One possible explanation that should be explored is that $C$. sativa is highly outbreeding but monoecious varieties are produced by inbreeding and may suffer from inbreeding depression. Nevertheless, most recently developed oilseed cultivars are monoecious, because eliminating male plants allows greater planting density and facilitates harvesting (Small, 2016).

\subsection{Thick Pericarps Protect Achenes from Fracturing}

Across all plants measured, my research revealed that the force required to fracture achenes increased proportionately to pericarp thickness (Figure 2.6). Compared to the achenes of ruderal plants, those of domesticated plants (hemp and marijuana collectively) had 20\% thicker pericarps and were $26.5 \%$ more resistant to fracturing (Table 3.1). Thus, the ruderal plants 
appear to be more susceptible to damage from pericarp fracture than the domesticated genotypes. This result initially appears counterintuitive since domesticated achenes are often protected from herbivory by humans whereas ruderal seeds are not. Thicker pericarps would seem to be desirable for protection against herbivory. Nevertheless, some cereal cultivars have been selected for thicker, more protective pericarps (Purugganan \& Fuller, 2009). For instance, maize and sorghum varieties that are used for making popcorn have evolved more protective pericarps (Anderson \& Williams, 1954). The thinner pericarps of the ruderal plants, like their relatively small size, may be another aspect where they are minimizing resource allocation to individual offspring. However, the relative needs of protecting the achenes of plants growing in nature or produced by humans is unclear. As well, the relationships of fracture resistance and the architecture and anatomy of achenes may be complex.

This study has shown that under domestication rather extensive alterations in achene structure have been established in different utilitarian Cannabis groups (Figure 4.2). Although associated with human kind since prehistoric times and a subject of great interest today, basic knowledge necessary for the development of $C$. sativa as a crop is rudimentary, and the data reported here are intended to contribute to a better understanding of its domestication status. The most significant modern crops differ from their wild ancestors in propagule features, often exhibiting the well-known "domestication syndrome," and this study demonstrated several of these trends, including loss of disarticulation, reduced hull, and larger size in the domesticate, as well as loss of camouflage. Differences were also found among the utilitarian classes. Marijuana strains had smaller, darker, achenes than hemp cultivars, presumably because hemp has been subjected to more selection for larger, lighter-coloured seeds. Fibre cultivars had larger achenes than oilseed cultivars, presumably because the former produces much fewer seeds allowing more 
energy to be channelled into them. The achenes of monoecious oilseed cultivars proved to be smaller than those of dioecious cultivars, presumably because the former suffer from inbreeding depression. These trends are consistent with a crop in its early stages of domestication for quite different purposes.

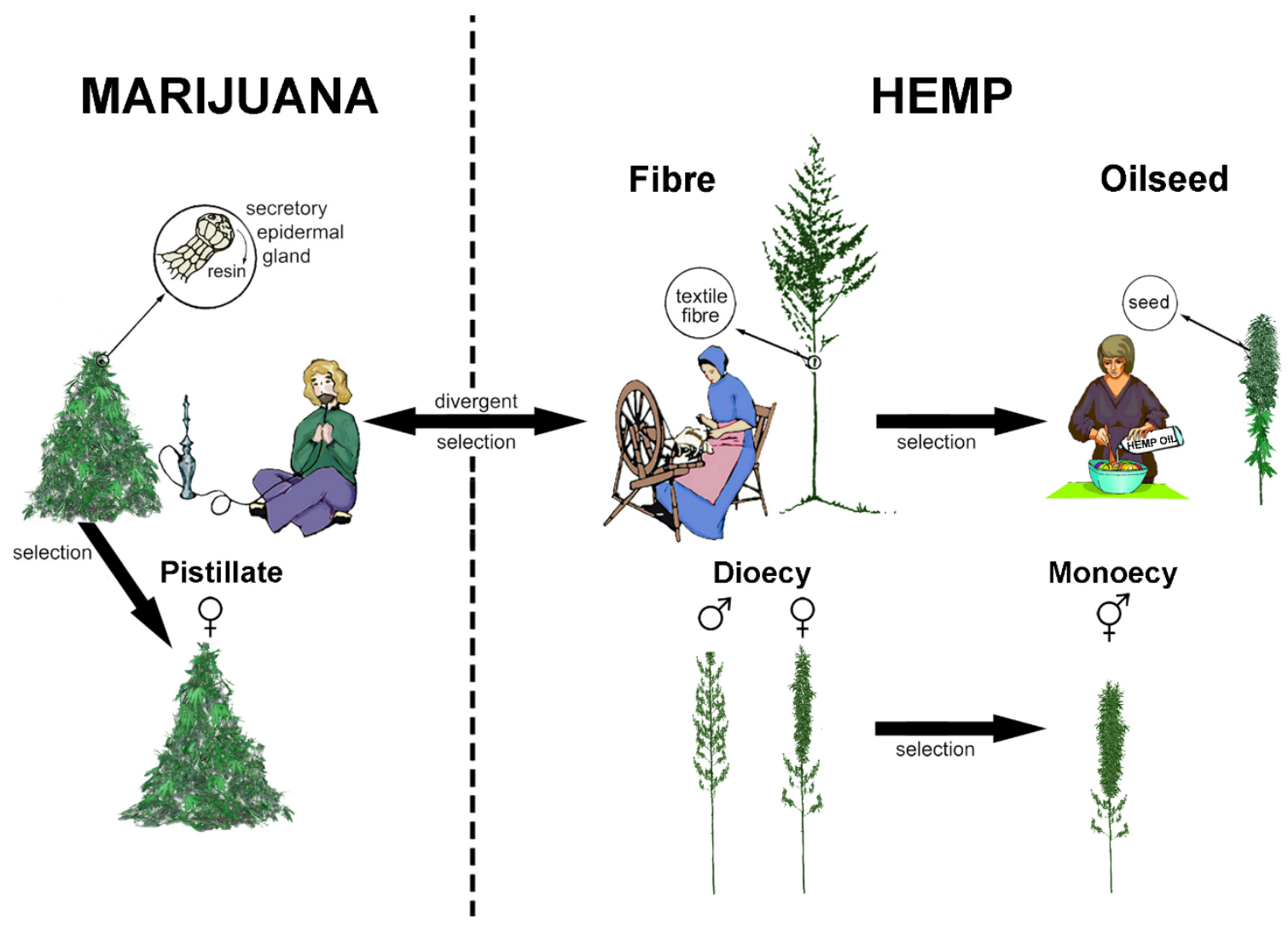

Figure 4.2 - Utilitarian Divergence of Cannabis sativa.

Whereas hemp is typically used for fibre and oilseed (where oilseed genotypes were likely derived from fibre genotypes), marijuana was domesticated for its resin production.

Wild plants were gathered by humans well before civilizations arose (Bettinger, Garvey, \& Tushingham, 2015). Agriculture may be as old as 15,000 years of age in some parts of the world (Chang, 1976), but modern crops are immensely more efficient at yielding useful products than their wild ancestors and early cultivated varieties. In developing modern crop varieties, humans have altered characteristics of the wild plants to make them more productive. Cereals 
(domesticated grasses harvested for their seeds) are the most important crops (Cakmak, 2008), and it has been established that the seeds of the most important cereals (corn, rice and wheat) have evolved dramatically in response to artificial selection from farmers and crop breeders (Doebley, Gaut, \& Smith, 2006). The changes involve: increased seed size; reduced seed dehiscence and size or strength of inedible (Zohary, 2004). Here I examined the morphological differentiation of these seed traits in Cannabis sativa. As will be noted, there are exact parallels between the morphological differentiation of grain crops versus their wild relatives and Cannabis sativa crops versus ruderal populations. These changes are adaptive in grain crops (Zohary, 2004) and likely adaptive in cannabis, increasing crop yield, although potentially reducing the ability of cultivated plants to survive in uncultivated conditions compared to their wild relatives (Zohary, 1969).

\subsection{Future Studies \& Limitations}

There are very few collections of wild material from southern Asia. Such collections (sometimes termed "kafiristanica" or "afghanica") may be of interest since Cannabis sativa has been speculated to have arisen in southern Asia (Small, 2015). Nevertheless, six collections were available for this study (see 2.3 Materials \& Methods - Specimens Examined), although the sample size was considered too limited to warrant inclusion in data collection and analysis. A particular effort should be made to collect seeds of this group from southern Asia, especially from higher elevation regions of northwestern India, and nearby areas (especially the Hindu Kush) of Afghanistan and Pakistan. As seen in Table 4.2, kafiristanica is much smaller and has a more pronounced basal attenuation even when compared with spontanea. 
Table 4.2 - One-way ANOVA comparing low-THC north-temperate ruderal accessions and high-THC semi-tropical (Indian) ruderal accessions.

\begin{tabular}{|c|c|c|c|c|}
\hline \multicolumn{5}{|c|}{ One-way ANOVA of Ruderal Accessions of C. sativa } \\
\hline & Kafiristanica & Spontanea & p-value & f-value \\
\hline 1000 Seed Mass & $5.63 \pm 2.61$ & $9.55 \pm 2.78$ & 0.0031 & 10.14 \\
\hline Length & $2.79 \pm 0.29$ & $3.62 \pm 0.30$ & $<0.0001$ & 37.7 \\
\hline Width & $2.21 \pm 0.25$ & $2.59 \pm 0.22$ & 0.0007 & 14.09 \\
\hline Perianth Adherance & $0.14 \pm 0.24$ & $0.68 \pm 0.23$ & $<0.0001$ & 27.2 \\
\hline Elongated Base & $2.63 \pm 0.44$ & $2.06 \pm 0.76$ & 0.089 & 3.07 \\
\hline
\end{tabular}

Very little is known about the seed dispersal of $C$. sativa, although it has been hypothesized that gravity, mammals, birds, insects, water and (of course) humans are significant vectors (Small, 2016). For example, the extent of survival through animal digestive systems is undocumented, to the best of my knowledge (McPartland \& Naraine, 2018). It would be interesting to examine how survival and dispersal are related to the hull characteristics documented in the present thesis. Wild markers could potentially be identified by sequencing these traits.

Because the achenes were grown in a variety of ecological contexts, I had limited opportunity to make conclusions about the role of evolution in the observed differences in cannabis achenes. There are several additional studies that would reinforce the conclusions. First, to understand how genetics influences seed morphology, all of the varieties should be cultivated in a common garden. Furthermore, experimental evolution, where we impose selection for either cannabinoid content or seed morphology, would help us to measure genetic correlations between achene morphology and secondary metabolite expression. Finally, I encourage future researchers to find the quantitative trait loci that are responsible for the achene phenotypes that we have observed. These experiments would help in concluding whether or not we have witnessed evolution of cannabis in this study. 


\subsection{Conclusion}

Humans have domesticated Cannabis sativa for different purposes (Figure 4.2). This study has found that there are rather extensive differences in achene structure among utilitarian groups. Although associated with humans since prehistoric times and a subject of great interest today, basic knowledge necessary for the development of $C$. sativa as a crop is rudimentary, and the data reported here are intended to contribute to a better understanding of its domestication process. The most significant modern crops differ from their wild ancestors in propagule features, often exhibiting the well-known "domestication syndrome," (Zohary, 2004) and this study demonstrated several of these trends, including loss of disarticulation, less hull, and larger size in the domesticate, as well as loss of camouflage. Differences were also found among the utilitarian classes. Marijuana strains had smaller, darker, achenes than hemp cultivars, presumably because hemp has been subjected to more selection for larger, lighter-coloured seeds. Fibre cultivars had larger achenes than oilseed cultivars, presumably because the former produces much fewer seeds allowing more energy to be channelled into them. The achenes of monoecious oilseed cultivars proved to be smaller than those of dioecious cultivars, presumably because the former suffer from inbreeding depression. These trends are consistent with a crop in its early stages of domestication for diverse human uses, as described in Section 1.4. 


\section{APPENDIX I - IMAGE ANALYSIS: MATLAB CODE}

I performed image analysis on images of achenes captured during data collection (See Section 2.2.4). Below, I describe the programming code I used to import colour images to MATLAB such that the image was converted into a matrix of grayscale estimates (Section $6.1 \& 6.2$ ) and to estimate the relative darkness of achene pericarp (Section 7.2).

\subsection{Programming code to import images to MATLAB and convert it into a matrix}

The images were cropped so that all pixels were representative of pericarp (no

background or perianth were included). The image was converted to grayscale and the grayscale cropped image was then imported to MATLAB and turned into a matrix using the following programming code.

I = imread('image.jpg'); \%import the image newI $=$ rgb2gray $(\mathrm{I}) ; \%$ converts the image from 3 colour RGB to 256-bit grayscale $\mathrm{M}=$ mean(newI(:)); \% single-precision mean of a vector

\subsection{Programming code to calculate greyscale of achenes}

The images were imported to MATLAB 2016b and, using MATLAB's enhanced image analysis, the average grayscale of each seed was calculated.

I = imread('image.jpg'); \%import the image newI = rgb2gray(I); \%converts the image from 3 colour RGB to 256-bit grayscale Figure imshow (I) imshow(newI) \%edge detection options BW1=edge(I,'sobel'); BW2=edge(I,'canny'); 


\section{BIBLIOGRAPHY}

Amaducci, S., Coluzzi, M., Zatta, A., \& Venturi, G. (2008). Flowering dynamics in monoecious and dioecious hemp genotype. Journal of Industrial Hemp, 13(1), 5-19.

Anderson, E. A., \& Williams, L. (1954). Maize and sorghum as a mixed crop in Honduras. Ann. Mo. Bot. Gard.(41), 213-221.

Bettinger, R. L., Garvey, R., \& Tushingham, S. (2015). Hunter-Gatherers: Archaeological and Evolutionary Theory (2nd ed.). New York: Springer.

Black, J. N. (1958). Competition Between Plants of Different Initial Seed Sizes in Swards of Subterrean Clover (T. subterranean L.) with Special Reference to Leaf Area and the Light Microclimate. Aust. J. Agric. Res., 9, 299 - 318.

Bouquet, R. J. (1950). Cannabis. Bulletin on Narcotics, 2(4), 14-30.

Brickell, C. D., Alexander, C., Cubey, J. J., David, J. C., Hoffman, M. H., Leslie, A. C., \& Malecot, V. (2016). International cod of nomenclature for cultivated plants (Ninth ed.). Leuven: International Society for Horticultural Science.

Cakmak, I. (2008). Enrichment of Cereal Grains with Zinc Agronomic or Genetic. Plant Soil, $302,1-17$.

Campbell, L. G., \& Snow, A. A. (2009). Can feral weeds evolve from cultivated radish (Raphanus sativus, Brassicaceae)? American Journal of Botany, 96, 498-506.

Caplan, D., Dixon, M., \& Zheng, Y. (2017a). Optimal rate of organic fertilizer during the vegetative-stage for cannabis grown in two coir-based substrate. HortScience, 52(9), 1307-1312.

Caplan, D., Dixon, M., \& Zheng, Y. (2017b). Optimal rate of organic fertilizer during the flowering-stage for cannabis grown in two coir-based substrate. HortScience, 52(12), 1796-1803.

Chang, T.-T. (1976). The Origin, Evolution, Cultivation, Dissemination and Diversification of Asian and African Rices. Euphytica, 425 - 441.

Chen, L. J., Lee, D. S., Song, Z. P., Suh, H. S., \& Lu, B.-R. (2004). Gene Flow from Cultivated Rice (Oryza sativa) to its Weedy and Wild Relatives. Annals of Botany, 93(1), 67-73.

Clarke, R., \& Merlin, M. (2013). Cannabis: Evolution and Ethnobotany. Berkley, London: University of California Press.

Darwin, C. (1859). On the Origins of Species by means of Natural Selection, or the Preservation of Favoured Races in the Struggle for Life . London: John Murray.

Darwin, C. (1868). The variation of animals and plants under domestication.

de Caraffa, B. V., Maury, J., Gambotti, C., Breton, C., Berville, A., \& Giannettini, J. (2002). Mitochondrial DNA variation and RAPD mark oleasters, olive and feral olive from 
Western and Eastern Mediterranean. Bronzini V. de Caraffa J. Maury C. Gambotti C. Breton A. Bervillé J. Giannettini, 104(6), 1209-1216.

De Meijer, E., Bagatta, M., Carboni, A., Crucitti, P., Cristiana Moliterni, V., Ranalli, P., \& Mandolino, G. (2003). The inheritance of chemical phenotype in Cannabis sativa L. Genetics Society of America, 163: 335-346.

Doebley, J. F., Gaut, B. S., \& Smith, B. D. (2006). The Molecular Genetics of Crop Domestication. Cell, 127, 1309 - 1321.

Edwards, G., \& Crawley, M. (1999). Rodent seed predation and seedling recruitment in mesic grassland. Oecologia, 118(3), 288-296.

Edwards, P. J. (1989). Insect Herbivory and Plant Defence Theory. In P. J. Grubb, \& J. B. Whittaker, Towards a More Exact Ecology (pp. 275-289). London: Blackwell Scientific Publications.

Fine, P. V., Mesones, I., \& Coley, P. D. (2004). Herbivores Promote Habitat Specialization by Trees in Amazonian Forests. Science, 305(5684), 663-665.

Fuller, D. Q., \& Allaby, R. (2009). Seed Dispersal and Crop Domestication: Shattering, Germination and Seasonality in Evolution Under Cultivation. Annual Plant Reviews, 38, $238-295$.

Garcia-Lara, S., Bergvinson, D. J., Burt, A. J., Ramputh, A. I., Diaz-Pontones, D. M., \& Arnason, J. T. (2004). The role of pericarp cell wall components in Maize weevil resistance. Crop Science, 44, 1546-1552.

Gressel, J. (2005). Crop Ferality and Volunteerism. Boca Raton, Florida: CRC Press.

Harlan, J. P. (1995). Agricultural Origins and Crop Domestication in the Mediterranean Region. Diversity, 2, 14 - 16.

Harlan, J. R., de Wet, J. M., \& Price, E. G. (1973). Comparative Evolution of Cereals. Evolution, $27,311-325$.

Herms, D., \& Mattson, W. (1992). The Dilemma of Plants: To Grow or Defend. The Quarterly Review of Biology, 67(3), 283-335.

Hicks, G. H., \& Dabney, J. C. (1897). The Superior Value of Large, Heavy Seeds. Washington, D.C.: Yearbook USDA 1896.

Hillig, K., \& Mahlberg, P. G. (2004). A Chemotaxonomic Analysis of Cannabinoid Variation in Cannabis (Cannabaceae). American Journal of Botany, 91(6), 966 - 975.

Janischevsky, D. E. (1924). A Form of Hemp in Wild Areas of Southeastern Russia. Učenye zapiski Saratovskogo Gosudarstvennogo imeni N.G. Černyševskogo Universiteta, 2(2), 3 -17 .

Jennings, D. L. (1986). Breeding for spinelessness in blackberries and blackberry-raspberry hybrids: a review. Acta Horticulturae, 183, 59-66. 
Jiang, H.-E., Li, X., Zhao, Y.-X., Ferguson, D. K., Hueber, F., Bera, S., . . Li, C.-S. (2006). A new insight into Cannabis sativa (Cannabaceae) utilization from 2500-year-old Yanghai Tombs, Xinjiang, China. Journal of Ethnopharmacology, 108, 414-422.

Kluyver, T. A., Charles, M., Jones, G., Rees, M., \& Osborne, C. P. (2013). Did Greater Burial Depth Increase the Seed Size of Domesticated Legumes? J. Exp. Bot., 64, 4101 - 4108.

Kolb, A., Ehrlén, J., \& Eriksson, O. (2007). Ecological and evolutionary consequences of spatial and temporal variation in pre-dispersal seed predation. Perspectives in Plant Ecology, Evolution and Systematics, 9(2), 79-100.

Konishi, S., Izawa, T., Lin, S. Y., Ebana, K., Fukuta, Y., Sasaki, T., \& Yano, M. (2006). An SNP caused loss of seed shattering during rice domestication. Science, 312, 1392-1396.

Li, H.-L. (1973). An archaeological and historical account of cannabis in China. Economic Botany, 28(4), 437-443.

Lucas, P. W., Peters, C. R., \& Arrandale, S. R. (1994). Seed-breaking forces exerted by orangutans with their teeth in captivity and a new technique for estimating forces produced in the wild. American Journal of Phys. Anthropol., 94, 365-378.

McCollum, G. D., \& Sinden, S. L. (1979). Inheritance study of tuber glycoalkaloids in a wild potato, Solanum chacoense bitter. American Potato Journal, 56(2), 95-113.

McPartland, J. M., \& Naraine, S. G. (2018). Experimental endozoochory of Cannabis sativa achenes. Med. Cannabis Cannabinoids, DOI:10.1159/000492971.

Meyer, R. S., DuVal, A. E., \& Jensen, H. R. (2012). Patterns and processes in crop domestication: an historical review and quantitative analysis of 203 global food crops. New Phytologist, 196(1), 29-48.

Ogg, A. G., \& Parker, R. (1989). Control of volunteer crop plants. Washington State University Extension Publication EB1523.

Pester, T. A., Westra, P., Anderson, R. L., Lyon, D. J., Miller, S. D., Stahlman, P. W., . . Wicks, G. A. (2000, November). Secale cereale interference and economic thresholds in winter Triticum aestivum. Weed Science, 48(6), 720-727.

Pianka, E. R. (1970). On R- and K- Selection. Am. Nat., 104, 592 - 597.

Pilson, D., \& Prendeville, H. R. (2004). Ecological effects of transgenic crops and the escape of transgenes into wild populations. Annual Reviews Ecology and Evolutionary Systems, 35, 149-174.

Porter, S. S. (2013). Adaptive divergence in seed color camouflage in contrasting soil environments. New Phytologist, 197: 1311-1320.

Purugganan, M. D., \& Fuller, D. Q. (2009). The nature of selection during plant domestication. Nature, 457, 843-848. 
Sadras, V. (2006). Evolutionary aspects of the trade-off between seed size and number in crops. Science Direct, 100(2-3), 125 - 138.

Sakai, A. K., Allendorf, F. W., Holt, J. S., Lodge, D. M., Molofsky, J., With, K. A., . . . McCauley, D. E. (2001). The population biology of invasive species. Annual Review of Ecology and Systematics, 32(1), 305-332.

Sakuma, S., Saloman, B., \& Komatsuda, T. (2011). The domestication syndrome genes responsible for the major changes in plant form in the Triticeae crops. Plant and Cell Physiology, 52(5), 738-749.

Sakuma, S., Salomon, B., \& Komatsuda, T. (2011). The Domestication Syndrome Genes Responsible for the Major Changes in Plant Form in the Triticeae Crops. Plant Cell Physiol., 52(5), 738 - 749.

Salisbury, E. J. (1942). The Reproductive Capacity of Plants; Studies in Quantitative Biology. London: Bell.

Schafer, M. G., Ross, A. A., Londo, J. P., Burdick, C. A., Lee, E. H., Travers, S. E., . . Sagers, C. L. (2011). The Establishment of Genetically Engineered Canola Populations in the U.S. PLOS One, 6(10).

Schultes, R. E. (1970). Random thoughts and queries on the botany of Cannabis. In R. B. Joyce, \& S. H. Curry, The botany and chemistry of Cannabis (pp. 11 - 38). London: J. and A. Churchill.

Serebriakova, T. Y., \& Sizov, I. A. (1940). Cannabinaceae Lindl. In N. I. Vavilov, Kilturnaja Flora SSSR (Flora of Cultivated Plants) (Vol. 5, pp. 1 - 53). Moscow-Leningrad, Kolos: State Printing Office.

Small, E. (1974). Morphological variation of achenes of Cannabis. Canadian Journal Botany, 53: 978-987.

Small, E. (1978). A numerical taxonomic analysis of the Daucus carota complex. Canadian Journal of Botany, 56(3), 248-276.

Small, E. (1984). Hybridization in the domesticated-weed-wild complex. In Plant biosystematics (pp. 195-210).

Small, E. (2015). Evolution and classification of Cannabis sativa (Marijuana, Hemp) in relation to human utilization. The botanical Review, 81(3):189-294.

Small, E. (2016). Cannabis: a complete guide. Boca Raton: CRC Press.

Small, E. (2017). Classification of Cannabis sativa in relation to agriculture, biotechnological, medical and recreational utilization. In S. Chandra, H. Lata, \& M. A. ElSohly, Cannabis sativa L.: botany and biotechnology (pp. 1-62). Berlin: Springer-Verlag.

Small, E., \& Antle, T. (2007). A study of cotyledon asymmetry in Cannabis sativa L. Journal of Industrial Hemp, 12(1), 3-14. 
Small, E., \& Beckstead, H. D. (1973). Cannabinoid phenotypes in Cannabis sativa L. Nature, 245, 147-148.

Small, E., \& Cronquist, A. (1976). A practical and natural taxonomy for Cannabis. Taxonomy, 25(4), 405-435.

Small, E., Pocock, P., \& Cavers, P. B. (2003). The biology of Canadian weeds. 119. Cannabis sativa L. Can J Plant Sci(83), 217 - 237.

Stephens, S. G. (1965). The effects of domestication on certain seed and fiber properties of perennial forms of cotton, Gossypium hirsutum L. The American Naturalist, 99(908), 355-372.

Stevens, M. (2007). Predator perception and the interrelation between different forms of protective coloration. Proceedings of the Royal Society B: Biological Science, 274:14571464.

Stevens, M., \& Merilaita, S. (2009). Defining disruptive coloration and distinguishing its functions. Phil. Trans. R. Soc. B, 364, 481-488.

Terral, J.-F., Tabard, E., Bouby, L., Ivorra, S., Pastor, T., Figueiral, I., . . This, P. (2010). Evolution and history of grapevine (Vitis vinifera) under domestication: new morphometric perspectives to understand seed domestication syndrome and reveal origins of ancient European cultivars. Annals of Botany, 105(3), 443-455.

Vavilov, N. I. (1931). The Role of Central Asia in the Origin of Cultivated Plants. Bulletin of Applied Botany, Genetics, and Plant Breeding, 26(3), 3 - 44.

Zohary, D. (1969). The Progenitors of Wheat and Barley in Relation to Domestication and Agricultural Dispersal in the Old World. In P. J. Ucko, \& G. W. Dimbleby, The Domestication and Exploitation of Plants and Animals (pp. 47 - 66). London, UK: Duckworth.

Zohary, D. (2004). Unconcious Selection and the Evolution of Domesticated Plants. Economic Botany, 58(1), 5 - 10. 